\title{
Caracterização da resposta de grupos de genótipos de arroz submetidos à deficiência hídrica no periodo reprodutivo
}

\author{
MARIA THEREZA RICCI SARTORI \\ - Engenheira Agrônoma -
}

Orientadora: Dra. BEATRIZ DA SILVEIRA PINHEIRO

Dissertação apresentada à Escola
Superior de Agricultura "Luiz de
Queiroz", da Universidade de São
Paulo, para obtenção do título de
Mestre em Ciencias, Área de
Concentração:
Bioquimica de Plantas.

\author{
Piracicaba \\ Estado de São Paulo - Brasil \\ Agosto de 1996
}


Dados Internacionais de Catalogação na Publicação (CIP)

DIVISĀO DE BIBLIOTECA E DOCUMENTAÇĀ̄O - Campus “Luiz de Queiroz"/USP

\section{Sartori, Maria Thereza Ricci}

Caracterização da resposta de grupos de genótipos de arroz submetidos à de deficiência hidrica no periodo reprodutivo / Maria Thereza Ricci Sartori. - - Piracicaba, 1996.

84p. : Il.

Dissertação (mestrado) - - Escola Superior de Agricultura Luiz de Queiroz, 1996.

Bibliografía.

1. Arroz de sequeiro - Deficiência hidrica 2. Arroz de sequeiro - Genótipo 3. Arroz de sequeiro - Melhoramento 4. Arroz de sequeiro - Resistência à seca I. Titulo

CDD 633.18 


\section{Caracterização da resposta de grupos de genótipos de arroz submetidos à deficiência hidrica no periodo reprodutivo}

Aprovado em: 13/11/96

Comissão Julgadora:

Dra. Beatriz da Silveira Pinheiro

Prof. Dr. Antonio Augusta Lucchesi

CNPAE / EMBRAPA

Dr. OrIando Peixoto de Morais

ESALQ/USP

CNPAF/EMBRAPA

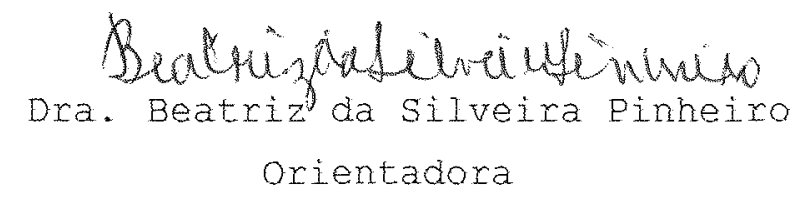


Aos meus pais, ofereço.

Ao meu esposo, dedico. 
A Dra. Beatriz da Silveira Pinheiro, pela amizade e orientação;

Ao Prof. Antonio Augusto Lucchesi, pela amizade e apoio;

Ao Dr. Francisco Zimermamm, pelo auxílio nas análises estatísticas;

Aos funcionários e estagiários do Laboratório de Eisilogia Vegetal do Centro Nacional de Pesquisa de Arroz e Feijão - CNPAF/EMBRAPA, pela amizade e auxílio na condução do experimento de campo;

À Empresa de Pesquisa, Assistência Técnica e Extensão Rural - EMPAER/MT, pela oportunidade de realização do curso de mestrado;

À EMBRAPA, pela bolsa de estudos concedida;

Ao CNPAF/EMBRAPA, pela utilização de suas dependências;

Aos demais que contibuiram direta ou indiretamente para a realização deste trabalho:

MEUS SINCEROS AGRADECIMENTOS 


\section{INDICE}

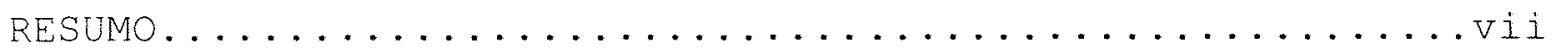

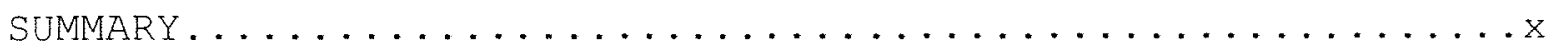

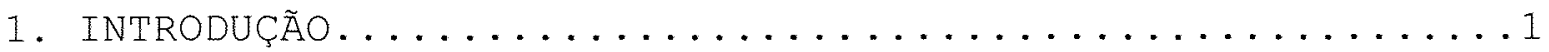

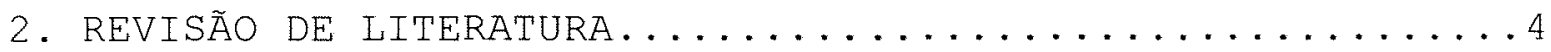

2.1. Mecanismos de resistência à seca..............

2.2. Características da planta em resposta ao

déficit hídrico.......................

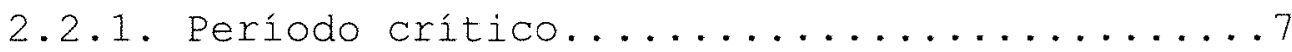

2.2.2. Reações da planta à seca..............

2.3. Melhoramento visando resistência à seca........20

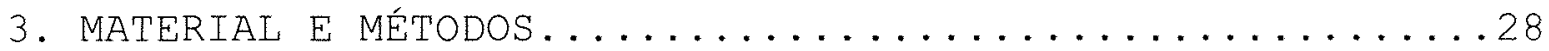

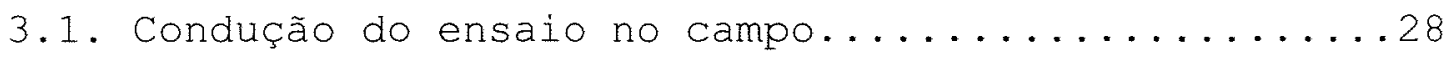

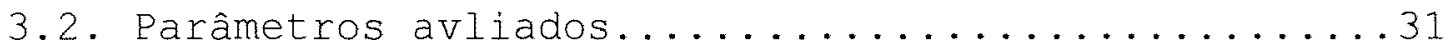

3.2.1. Conteúdo relativo de água no solo.......32

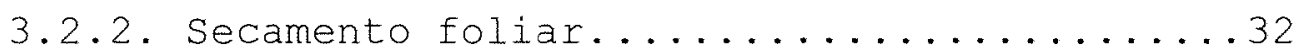

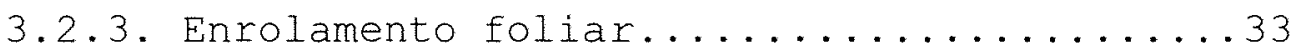

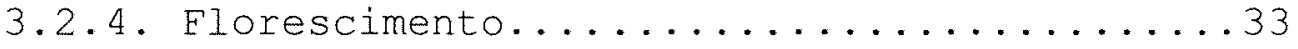

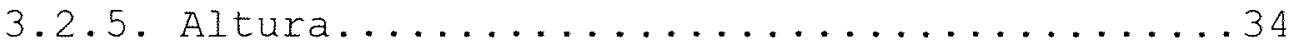

3.2.6. Porcentual de exposição de panícula......34

3.2.7. Eertilidade de espiguetas.............34

3.2.8. Biomassa total na fase reprodutiva......35

3.2.9. Potencial hídrico em folhas ao meio

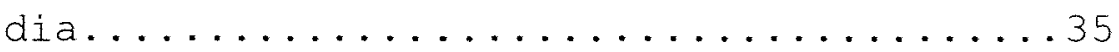

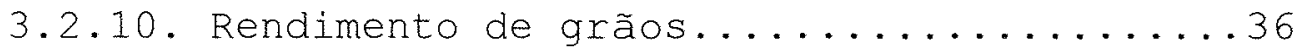

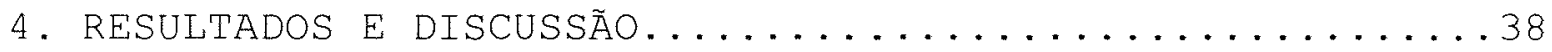

4.1. Caracterização da intensidade da deficiência

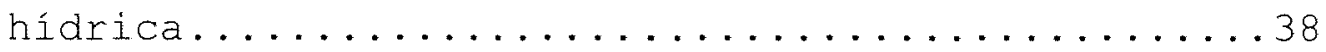

4.2. Efeito da deficiência hídrica sobre os parâmetros

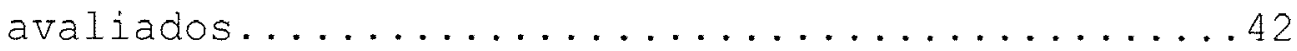


4.2.1. Florescimento................43

4.2.2. Estado hídrico da planta..........45

4.2.3. Características visuais............46

4.2.4. Exposição da panícula e fertilidade de espiguetas......................

4.2.5. Altura de planta e biomassa..........54

4.2.6. Rendimento e avaliação global de resistência à seca...............57

4.3. Associações entre o rendimento e os vários parâmetros de resistência à seca............663

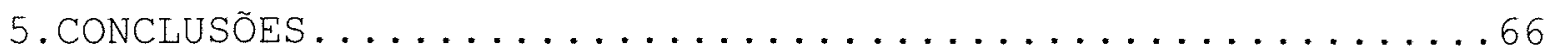

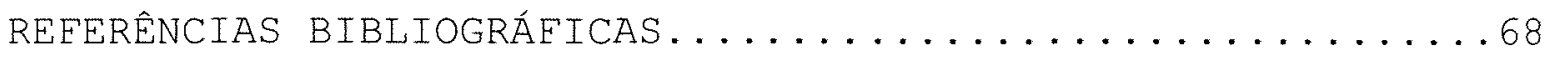

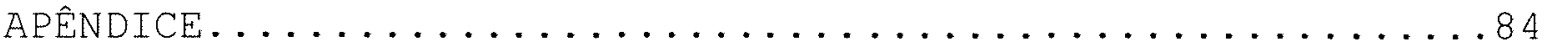




\title{
CARACTERIZAÇÃO DA RESPOSTA DE GRUPOS DE GENÓTIPOS DE ARROZ SUBMETIDOS À DEFICIÊNCIA HÍDRICA NO PERÍODO REPRODUTIVO.
}

\author{
Autor: Maria Thereza Ricci Sartori \\ Orientadora: Dra. Beatriz da Silveira Pinheiro
}

\section{RESUMO}

O trabalho foi realizado na sede do Centro Nacional de Pesquisa de Arroz e Eeijão da EMBRAPA, situado no Municipio de Santo Antônio de Goiás, com o objetivo de avaliar a resistência à seca de cinco grupos de genitores utilizados nos programas de melhoramento de arroz de sequeiro e classificados como sequeiro favorecido, sequeiro tradicional, sequeiro melhorado africano, sequeiro melhorado brasileiro e irrigado.

Dois experimentos de campo idênticos foram implantados tardiamente para coincidir o período reprodutivo dos genótipos com o início da estação seca na região. 0 delineamento experimental foi 0 de blocos completos balanceados em grupos. Utilizou-se cinco grupos, os quais constituiam as parcelas, e dezoito genótipos por grupo, os quais constituiam as subparcelas.

As chuvas cessaram no $78^{\circ}$ dia após a semeadura, quando todos os genótipos se encontravam na fase reprodutiva. Um dos experimentos não recebeu irrigação suplementar por 25 dias para induzir déficit hidrico (ExpI) enquanto o outro foi mantido sob boa disponibilidade de água (ExpII). 
- potencial da água apresentou uma queda similar para todos os grupos até o $15^{0}$ dia, após os quais o grupo de arroz irrigado apresentou uma maior redução desse parâmetro em relação aos grupos de sequeiro, chegando ao final do ciclo de secamento com um potencial de $-2.2 \mathrm{MPa}$. Os grupos de sequeiro permaneceram entre $-1.7 \mathrm{MPa}$ e $-1.9 \mathrm{MPa}$, denotando uma maior capacidade de evasão da deficiência hídrica.

A diferença no estado hídrico dos materiais entre os grupos traduziu-se em diferenças significativas nos vários parâmetros de avaliação da resistência à seca.

os grupos de sequeiro africano e melhorado apresentaram um menor enrolamento foliar, maior exposição da panicula e fertilidade de espiguetas e consequentemente uma melhor classificação na escala de avaliação de resistência à seca.

O grupo de sequeiro tradicional teve seu desempenho prejudicado no que se refere aos parâmetros visuais, dado ao confundimento entre a brusone nas folhas e os sintomas de enrolamento e secamento. Contudo apresentou boa fertilidade de espiguetas, o que é um bom indício de resistência à seca. Por sua vez o sequeiro favorecido comportou-se como um grupo intermediário entre o sequeiro e o irrigado, o que era de esperar, dado que se originou de cruzamentos entre genitores desses dois grupos.

Apesar das diferenças significativas entre grupos para o fator rendimento, não foi detectada interação entre grupo e regime hídrico. O grupo de sequeiro melhorado teve o maior rendimento, seguido do sequeiro africano. Os demais grupos apresentaram rendimentos similares.

- rendimento sob condições de deficiência hídrica associou-se de forma estreita à nota de seca $(0.878 * *)$ e à fertilidade de espiguetas $\left(0.600^{*}\right)$. O coeficiente de 
correlação entre o rendimento sob boa disponibilidade de água e sob deficiência hídrica foi de $0.53^{* *}$.

Apesar das diferenças entre grupos no que se refere aos parâmetros de resistência à seca, a nota de avaliação detectou uma diferença entre os extremos de apenas 2.1 pontos (escala 1-9) no desempenho dos grupos. Entretanto as variações dentro dos grupos denotam a existência de variabilidade para resistência à seca que pode ser usada em benefício do melhoramento.

Possivelmente parte do sucesso do grupo de sequeiro melhorado resida no uso de genitores elite do grupo japonica na sua composição. O pior desempenho dos materiais de sequeiro favorecido frente aos demais grupos de sequeiro, demonstra o risco de cruzar japonica com indica de forma aleatóría. 


\section{RESPONSE OF RICE GENOTYPES GROUPS TO DROUGHT DURING REPRODUCTIVE STAGE}

Author: Maria Thereza Ricci Sartori

Adviser: Beatriz da Silveira Pinheiro

\section{ABSTRACT}

The study was undertaken at the headquarters of the National Research Center for Rice and Beans of EMBRAPA, located in Santo Antônio de Goiás, state of Goiás. The objective was evaluating the response to drought of five groups of genotypes used as progenitors in the upland rice national programs. Those groups were classified as favored upland, traditional upland, african upland, improved upland and irrigated rice.

Two identical field experiments were installed late in the normal growth season to match reproductive development with the onset of dry season. They obeyed a complete balanced block design whose plots were the five genotype groups and the subplots were 18 genotypes per group.

The rains subsized in the 78th day afer sowing, when all genotypes were at the reproductive stage. One of the experiments was kept sprinkler irrigated to serve as a control whereas the other was left without irrigation for 23 days to induce water stress.

The water stressed groups showed significant differences in water potential since the $15^{\text {th }}$ day. The 
irrigated group showed a higher decrease in this parameter than the upland groups, attaining $-2,2 \mathrm{MPa}$ at the end of the stress period. The upland groups remained between -1.7 and 1,9 MPa, showing a higher avoidance ability than the irrigated group.

These differences in water status among groups translated into significant differences in the various evaluation parameters of drought resistance. The african and improved upland groups showed lesser leaf rolling, higher panicle exertion and spikelet fertility and consequently a better rating on the drougth evaluation system.

The traditional upland group had its performance impaired by high suscetibility to leaf blast, which caused leaf damage and counfounded the visual score of leaf rolling and leaf drying. Nevertheless, this group showed a good index of spikelet fertility, which is the best indicator of drought resistance.

The favored upland group behaved as intermediate between the irrigated and the upland groups, which was expected, given its origin.

Although the significant differences of yield among groups, there was no interaction between water treatments and groups. The improved upland showed the highest yield, followed by the african upland. The other groups presented similar yields.

Yield under stressed conditions was highly correlated to the drought evaluation score $(r=0.878 * *)$ and to spikelet fertility $(r=0,600 * *)$. The correlation coefficient between yield in the stressed experiment and that of the irrigated control was $0,53^{* *}$.

Although consistent differences in drought resistance among groups were detected, the drought evaluation score 
range was of only 2.1 points in a 1 to 9 scoring system. However the differences whithin groups indicate genotypic differences that can be used on breeders benefit.

Problably part of the success of the improved upland group lies in the use of elite japonica genitors. The poorer performance of the favored upland as compared to the other upland groups demonstrates the risk of indiscriminate crossing between indica and japonica germplasm. 


\section{INTRODUÇÃO}

A cultura do arroz ocupa um papel destacado no país, tanto do ponto de vista econômico como social. Sua presença na dieta básica dos brasileiros é generalizada em todas as regiões e em todas as classes sociais, constituindo-se em importante fonte de calorias e proteínas (EMPRESA BRASILEIRA DE PESQUISA AGROPECUÁRIA EMBRAPA, 1994).

o cultivo do arroz de sequeiro é o sistema mais adotado na Região dos Cerrados, sendo responsável por mais de 90\% da produção de arroz nesta região(SANTANA, 1994). Sua produtividade é baixa e bastante variável de um ano para outro, principalmente devido à ocorrência de estiagens prolongadas (EMBRAPA, 1981).

De acordo com STEINMETz et al. (1988), - regime pluviométrico característico da região dos cerrados apresenta um total médio de $1.500 \mathrm{~mm}$ em que cerca de $85 \%$ das chuvas ocorrem de outubro a abril. A coincidência de veranicos com a fase reprodutiva da cultura pode levar a perda total da produção. Assim, a maior parte dos cerrados é 
classificada como de risco intermediário ou desfavorecido para o arroz de sequeiro.

Desde o inicio da exploração dos cerrados na década de 60 até meados da década de 80, o arroz de sequeiro desempenhou básicamente 0 papel de cultura pioneira, precedendo a implantação de pastagens ou outras culturas. Tal tipo de exploração é notadamente avesso ao uso de insumos agrícolas ou de tecnologias, pois sua finalidade principal é abertura da área.

Para atender a demanda de variedades para esse sistema, os programas de melhoramento da região tem como meta a estabilidade do rendimento e como uma das principais prioridades, o aumento da resistência à seca.

- sistema de cultivo de sequeiro para abertura de área, apesar de ainda predominante, vem sendo gradativamente reduzido devido à redução de áreas sob cerrado nativo.

Mas a cultura apresenta um excelente potencial para retomar seu crescimento na região. Vem expandindo seu uso em consorciação com forrageiras, visando a recuperação de pastagens degradadas (KLUTHCOUSKI \& YOKOYAMA, 1994) e como componente de sistemas agrícolas de sequeiro, principalmente em rotação com soja. (SEGUY \& BOUZINAC, 1992).

Tais sistemas preconizam o uso de maior quantidade de insumos e de tecnologias e por isso o produto final deve, necessariamente, ser competitivo no mercado. De acordo com SANTANA, 1994, o brasileiro está substituindo o grão tipo longo e largo, típico de sequeiro, pelo longo e fino (agulhinha) do sistema irrigado.

Em face deste novo panorama para a cultura do arroz de sequeiro, a resistência a seca passa a ser uma 
prioridade secundária, frente a busca de uma melhor qualidade de grãos.

Assim os programas de melhoramento da região vem diminuindo a proporção de genótipos de sequeiro do grupo Japonica em cruzamentos, ampliando, por outro lado, - uso de variedades de arroz irrigado e de sequeiro favorecido, do grupo Indica na obtenção de novas variedades de sequeiro com melhor aparência de grãos.

Esta estratégia pode ter como consequência a redução do nível de resistência à seca das novas linhagens em relação ao das atuais variedades.

o presente trabalho foi realizado com o objetivo de dar suporte aos programas de melhoramento de arroz de sequeiro, propiciando-lhe informações sobre grupos de genótipos utilizados comumente nos cruzamentos, com relação ao seu comportamento na presença de deficiência hídrica. 


\section{REVISÃO DE IITERATURA}

\subsection{Mecanismos de Resistência à seca}

O fenômeno da seca sempre ocorreu nas várias regiões do mundo, mas ultimamente tem se tornado um fator mais frequente. Isto não se deve necessariamente a alguma alteração global da Terra, através do fenômeno "efeito estufa", mas devido a uma intensificação da exploração do ambiente (MCWILLIAN, 1989).

Segundo O'TOOLE \& CHANG (1979), a seca é o segundo maior fator limitante na produção de arroz nos países asiáticos, ultrapassada apenas por doenças e insetos.

Aspectos de resistência à seca vêm sendo cada vez mais pesquisados, e o entendimento do comportamento da planta em relação ao déficit hídrico torna-se necessário.

$$
\text { Vários autores definem } 0 \text { termo }
$$

"resistência à seca". JONES et al. (1981) a define como um termo genérico usado para abranger uma série de mecanismos pelos quais as plantas suportam períodos de déficit hídrico. TURNER (1979) a descreve como a habilidade de espécies 
cultivadas ou variedades para desenvolverem-se e produzirem satisfatoriamente em áreas sujeitas a periodos de déficit hídrico, o que contrasta com a definição em termos ecológicos que leva em consideração apenas a habilidade da planta em sobreviver nestes períodos. KRAMER (1980) prefere - termo "tolerância à seca" para definir a habilidade da planta para sobreviver à seca.

Segundo STEPONKUS et al (1980), a resistência à seca da maioria das espécies mesófitas cultivadas não pode ser atribuída a um único mecanismo. Pelo contrário, a resistência à seca das espécies cultivadas deve ser considerada como um complexo de mecanismos interagindo, todos contribuindo para o desempenho da planta.

LEVITT (1972) classificou os mecanismos de resistência à estresses em geral em duas categorais: evasão ou capacidade de excluir o estresse, e tolerância ou capacidade de sobreviver ao estresse interno. Para o caso especifico do estresse devido ao déficit hídrico são identificadas diferentes categorias dentro da classificação geral. Desta forma, plantas ou organismos que exercem o mecanismo de evasão se diferenciam em gastadores ou conservadores de água. Os que exercem o mecanismo de tolerância podem evitar ou tolerar a desidratação. Em sua classificação o escape não é considerado como um mecanismo de resistência à seca.

De acordo com BANNISTER (1976), uma classificação bem aceita é a que pertence a LEVITT, SULIVAN \& KRULL. Neste sistema, resistência à seca também é considerada como um termo geral, sendo que a habilidade dos tecidos em opor-se ao baixo potencial hídrico é denominada "tolerância à seca", enquanto os vários meios que capacitam a planta a evitar ao baixo potencial hídrico seria 
denominado "escape à seca". Deste modo o escape à seca pode ser considerado uma reação ecológica, enquanto a tolerância seria uma reação fisiológica e protoplasmática. Nesta definição, a habilidade da planta para resistir à seca em uma situação natural é composta de escape e tolerância.

May \& Milthorpe, citados por TURNER (1979), classificam a resistência à seca em três tipos: o escape, a tolerância à seca com a manutenção de alto potencial hídrico nos tecidos da planta e a tolerância à seca com baixo potencial hídrico. Escape é a habilidade da planta em completar seu ciclo de vida antes do desenvolvimento do déficit hídrico no solo e na planta. Tolerância com alto potencial hídrico é a habilidade da planta em suportar periodos de escassez de chuva mantendo um alto conteúdo de água nos tecidos.

KRAMER (1980) também propõe a subdivisão de resitência à seca em duas categorias: escape e tolerância, sendo que ao invés de escape, o autor prefere o termo evasão; a tolerância à seca é subdividida ainda em "adiamento da desidratação" e "tolerância ao dessecamento".

MCWILLIAN (1989), usando a terminologia de LEVITT (1980), também coloca que a resitência à seca pode ser alcançada através de escape e tolerância. O escape também envolve uma maturidade precoce para evitar um severo déficit hídrico, enquanto a tolerância envolve outro tipo de evasão ou adiamento da desidratação pela manutenção da absorção de água ou redução da perda da mesma, ou a própria tolerância ao dessecamento, a qual normalmente envolve ajustamento osmótico.

De acordo com O'TOOLE \& CHANG (1979), a classificação mais simples e mais comumente aceita é a que 
considera resistência à seca como a soma da evasão e da tolerância.

Pode-se observar que as classificações são similares, diferindo apenas na terminologia utilizada. Num sentido mais amplo, pode-se concluir que a resistência à seca seria formada pela soma de todos os mecanismos citados (escape, evasão e tolerância) além da capacidade de recuperação da planta. Contudo CHANG \& LORESTO (1986) consideram a resistência à seca e a habilidade de recuperação como duas características independentes.

\subsection{Características da planta em resposta ao déficit hídrico}

\subsubsection{Período crítico}

Diferentes estágios de desenvolvimento e crescimento podem variar em sensibilidade ao déficit hídrico ou seja ao nível do estado hídrico da planta requerido para não prejudicar seu desempenho (STEPONKUS et al., 1980).

O'TOOLE \& MOYA (1981) verificaram uma relativa falta de sensibilidade do rendimento ao estresse hídrico na fase vegetativa e uma alta sensibilidade na fase reprodutiva.

$$
\text { O desenvolvimento reprodutivo dos cereais, }
$$

que compreende $\circ$ desenvolvimento da inflorescência, o florescimento, a polinização e a fertilização representa o estágio de desenvolvimento da cultura mais sensivel à seca (BOYER \& MCPHERSON, 1976). O défict hídrico nas fases média e final do período reprodutivo da planta de arroz causa 
maiores perdas na produção do que na fase inicial de diferenciação do primórdio floral (EMBRAPA, 1984).

o período crítico para estresse hídrico em arroz, em termos de intervalo, é de aproximadamente vinte dias antes do florescimento até 10 dias após o mesmo (DeDatta, 1975 e Matsushima, 1968 citados por JONES, 1981).

Um período ainda mais crítico, segundo Matsushima (1962), citado por YOSHIDA (1975), seria o período de aproximadamente onze dias antes do florescimento até o mesmo.

O'TOOLE \& CHANG (1979) e O'TOOLE \& GARRITY (1984), indicam que a redução no rendimento ou sensibilidade ao estresse na fase reprodutiva pode ser classificado da seguinte maneira: florescimento > gametogênese $\geq$ iniciação da panícula > enchimento de grãos.

\subsubsection{Reações da planta à seca}

Várias são as reações da planta ao déficit hídrico, as quais demonstram sua maior ou menor susceptibilidade à seca.

As variedades diferem na sua habilidade para o rendimento (CHANG et al., 1974), assim num plantio realizado em condições de sequeiro, o rendimento não pode ser o único critério de avaliação da resistência à seca.

A redução de perdas de água pela transpiração é uma das adaptações que a planta possui para retardar a instalação do déficit hídrico, e vários são os mecanismos por ela utilizados.

O enrolamento foliar, é uma forma efetiva pela qual esta espécie semi aquática, assim como outras 
monocotiledôneas, modera perdas de água durante períodos de déficit hídrico foliar devido à alta demanda evapotranspirativa (O'TOOLE et al., 1979).

o ângulo foliar parece estar relacionado com o enrolamento foliar e também com os componentes da produção.

Variedades com folhas eretas tendem a minimizar a perda de água por transpiração em relação à variedades com folhas decumbentes porque enrolam mais facilmente (YOSHIDA, 1975; ALLURI \& VERGARA, 1976).

No trabalho de ALLURI \& VERGARA (1976), a varidade de folhas eretas reteve uma maior área foliar por perfilho após o estresse hídrico do que a com folhas decumbentes. Os autores concluem que as caracterísitcas das variedades tradicionais de arroz de sequeiro, tais como estatura alta, folhas longas e decumbentes, não favorecem sua resistência à seca, e que as folhas eretas são desejáveis.

CHANG et al. (1974) concluem que folhas longas ou moderadamente longas e ligeiramente decumbentes são associadas com plasticidade em enrolar e desenrolar quando 0 estresse hídrico interno ocorre durante o perfilhamento. Tais folhas podem desenrolar quando o estresse é parcialmente diminuído em manhãs frescas. Entretanto, variedades susceptiveis à seca com folhas longas raramente desenrolam quando o estresse hídrico é prolongado. $\mathrm{Na}$ maioria das variedades semi-anãs com folhas curtas e eretas, o enrolamento foliar começa em um estágio mais avançado, num potencial hídrico menor (mais negativo), indicando uma resposta menos sensivel (CHANG et al., 1974; DINGKUHN et al., 1989). Quando finalmente apresentam 
enrolamento, as folhas dobram-se firmemente em forma de tubo e não desenrolam à noite (CHANG et al., 1974).

$$
\text { o trabalho de PINHEIRO et al. }
$$

mostra uma relação de caráter negativo entre o ângulo da folha e a percentagem de fertilidade das espiguetas. Os autores especulam que a relevância do ângulo da folha na determinação da produtividade pode estar ligada à observação de que, no período de florescimento e enchimento de grãos, folhas longas e decumbentes tem dificuldade de enrolamento.

o enrolamento foliar durante o estresse hídrico pode prevenir perdas por transpiração mas leva a um fechamento dos estômatos, assim as trocas gasosas nas células são reduzidas e a fotossíntese decresce. O enrolamento reduz também a superfície fotossintética e a área de absorção de luz e assim conduz a uma redução dos níveis de assimilados (SINGH \& MACKILL, 1991).

o enrolamento foliar pode ser um indicador usual do potencial hídrico foliar e é correntemente utilizado por melhoristas na seleção para a evasão ao estresse hídrico em arroz (JONES, 1979; O'TOOLE \& CRUZ, 1980).

Segundo JONES (1979), O'TOOLE \& CRUZ (1980) e TURNER et al. (1986a), a relação entre o potencial da água na folha e o enrolamenro foliar, no decorrer do desenvolvimento do estresse hídrico na planta, é variável de acordo com o ecossistema para o qual a variedade é adaptada. As variedades de sequeiro enrolam suas folhas a um potencial mais alto (menos negativo) do que as variedades irrigadas.

JONES (1979), encontrou um maior coeficiente de correlação entre o potencial da água na folha e enrolamento foliar em variedades de sequeiro $(0,73)$ do que em variedades de irrigado $(0,44)$. 
Esta alta correlação entre o potencial hídrico e o enrolamento foliar nas variedades de sequeiro pode ser atribuída a um melhor sistema de absorção de água (O'TOOLE \& CRUZ, 1980 e STEPONKUS et al., 1980).

com base nestes resultados, o uso do enrolamento foliar como um índice do déficit hídrico da planta, utilizado como medida do potencial hídrico e como técnica de seleção para a tolerância à seca, é questionado por TURNER et al. (1986a), já que uma mesma nota de enrolamento pode significar valores diferentes de potencial hídrico foliar.

Por ser uma característica relativamente fácil de se observar, o enrolamento foliar deve ser medido pela manhã para avaliar a capacidade de reidratação noturna e, indiretamente avaliar o desenvolvimento radicular (O'TOOLE \& MOYA, 1978 e O'TOOLE \& CHANG, 1978). Geralmente, a relação entre o grau de enrolamento foliar e o potencial hídrico da folha é válida; entretanto, quando genótipos muitos divergentes são testados, variações nesta relação podem ocorrer (O'TOOLE \& MOYA, 1978, 1981 e DINGKUHN et al., 1989).

Segundo KRUPP et al. (1972), as variedades de sequeiro, em geral, apresentam um conteúdo relativo de água mais alto após três horas de déficit hídrico, que outras variedades. Assim sendo, os autores recomendam a taxa de secamento foliar como uma técnica simples utilizada para selecionar variedades melhor adaptadas para resistir ao dessecamento durante períodos de déficit hídrico.

o secamento foliar compromete a produção de uma cultura, principalmente devido à perda de superficie fotossintética potencial. Em condições de deficiência hídrica, normalmente, as plantas apresentam primeiramente um 
secamento das folhas mais velhas e depois das folhas mais novas, iniciando-se pelo ápice. Por isso, APARICIO-TEJO \& BOYER (1983) recomendam a seleção contra a senescência acelerada das folhas à baixos potenciais hídricos.

Segundo RENARD \& ALLURI (1981), o enrolamento foliar associado com o fechamento dos estomatos da face inferior é efetivo em controlar a transpiração, mas tanto o enrolamento como o fechamento dos estômatos aparentam serem mais sintomas do que mecanismos de evasão.

BoIs et al. (1984), em um estudo de controle estomático observaram que as variedades de sequeiro fecham seus estômatos a um potencial hídrico do solo de $-0,6$ a $-0,8$ bars, enquanto as variedades irrigadas os fecham precocemente, a um potencial hídrico do solo de $-0,4$ a $-0,5$ bars.

O'TOOLE \& CRUZ (1980) relatam que, em arroz a resitência estomatal da superficie superior e inferior da folha diferem em resposta ao estresse hídrico. Neste trabalho, à medida que o potencial hídrico foliar do meio dia torna-se mais negativo, a resistência da superficie inferior aumenta mais do que a da superficie superior. Estas diferenças, segundo os autores, pode ser devido a uma interação com o enrolamento foliar, o qual modifica o microclima da parte superior da folha com menor incidência de radiação solar, menor demanda evapotranspirativa e, possivelmente, menor concentração de gás carbônico.

Provavelmente, as características varietais mais importantes na eficiência para a absorção de água e resistência à seca são a morfologia de raiz e a taxa de desenvolvimento radicular (KRUPP et al., 1972). 
o desenvolvimento de um sistema radicular profundo e ramificado tem sido associado com a capacidade das variedades de arroz resistirem à seca (EMBRAPA, 1984).

De acordo com JOSHI (1968), acredita-se que as características comuns associadas a resistência à seca são um sistema radicular extenso para explorar a umidade da superfície e de níveis mais profundos do solo, e uma menor área foliar exposta a atmosfera para minimizar perdas de água. Assim, a planta pode fazer um uso mais econômico da água. Entre os atributos que influenciam o potencial de rendimento, o número de perfilhos férteis é de suprema importância. Isso decorre que, genótipos resistentes à seca são fracos em rendimento. Mas, em condições de seca, são genótipos que podem produzir razoavelmente.

Em experimentos conduzidos pelo IRRI em 1970, citados por KRUPP et al. (1972), uma variedade de sequeiro e outra de irrigado, plantadas em condições de submersão, não apresentaram diferenças no seu desenvolvimento radicular, já quando plantadas em condições de sequeiro, a variedade de sequeiro mostrou um maior desenvolvimento radicular.

BOIS \& COUCHAT (1983) compararam duas variedades de arroz de sequeiro consideradas tolerantes à seca - Iguape Cateto, variedade tradicional do Brasil, e IRAT13, variedade de origem africana. Constataram que, mesmo no período de défict hídrico, a variedade Iguape Cateto consegue manter um mínimo crescimento radicular, enquanto IRAT13 não apresenta crescimento algum. Após a reidratação, a taxa de alongamento de raiz da Iguape Cateto é superior ao do IRAT13. 
De acordo com YOSHIDA \& HASEGAWA (1982), a relação raiz/parte aérea em profundidade, é correlacionada com resistência à seca em condições de campo.

Trabalhos do INTERNATIONAL RICE RESEARCH INSTITUTE - IRRI (1989) também mostram que genótipos com parte aérea mais densa demonstram maior susceptibilidade à seca. Os resultados dos estudos genéticos realizados por este Instituto são comentados a seguir: análises do coeficiente de variação mostram que plantas mais altas e com parte aérea mais densa são mais susceptíveis à seca, em campo, na fase reprodutiva. Plantas com raízes espessas são resistentes à seca em campo. Raízes profundas e rasas variam em sua reação à resistência à seca. O efeito direto da área foliar total na resistência à seca é insignificante $(P=0,086)$, entretanto, o coeficiente de correlação genotípica entre as duas características é negativo e altamente significante $(r=-0,465)$. Segundo os autores, a alta associação pode ser atribuída a um grande efeito indireto do peso da matéria seca da parte aérea $(\mathrm{P}=0,786)$. Isto depende do número de perfilhos e de folhas (baixo número de perfilhos e pequena área foliar demonstrariam resistência a seca).

PASSIOURA (1972) tem demonstrado que, pela manipulação do sistema radicular de trigo, a planta pode ser induzida a reduzir sua área foliar e assim conservar água suficiente na fase vegetativa para prover a fase reprodutiva e produzir algum grão.

Com base na forte associação entre certas características radiculares e da parte aérea, plantas tendo sistema radicular profundo e espesso, moderada habilidade de perfilhamento, folhas curtas e estreitas, e altura intermediária de planta teriam, provavelmente, melhor 
performance e rendimento mais estáveis em ambientes sujeitos à seca (IRRI, 1989).

O trabalho de CHAUDHARY \& GHILDYAL (1970) mostra um maior desenvolvimento radicular a temperaturas do solo de $32^{\circ} \mathrm{C}$, diminuindo o estresse nas folhas das plantas de arroz neste período.

MANBANI \& LAL (1983a) mostraram uma correlação positiva do potencial da água da folha e do desenvolvimento do estresse hídrico com a densidade radicular em profundidade (15 a $20 \mathrm{~cm}$ ), enquanto a densidade radicular superficial pouco influenciou. Os autores sugerem que as alterações no potencial hídrico foliar ao longo do ciclo de secamento podem ser usadas para a seleção de variedades de arroz com evasão à seca.

MANBANI \& LAL (1983b) mostram que o regime hídrico do solo afeta a densidade e o ângulo de penetração das raízes, e que o estresse hídrico diminui a densidade radicular média, mas aumenta a penetração vertical das raízes.

A resistencia longitudinal ao fluxo de água, ou seja, a taxa com que a áqua do solo é transportada do solo até a parte aérea também é de grande importância (PASSIOURA, 1982). O autor vereficou que o pequeno diâmetro do xilema no eixo seminal das plantas, condiciona uma baixa resistência ao fluxo de água. ALLURI et al. (1982) trabalhando com trinta e cinco variedades de arroz, encontraram uma correlação positiva entre o diâmetro médio de raízes e a avaliação da seca em campo.

No trabalho de MANBANI \& LAL (1983b), o rendimento de grãos foi linearmente relacionado com a densidade radicular à profundidade de $25 \mathrm{~cm}$. Já no trabalho 
de PINHEIRO \& RAISSAC (1991), a fertilidade de espiguetas e - alto potencial da água se associaram com a densidade de raízes apenas na camada de 60 a $80 \mathrm{~cm}$ de profundiade do 5010 .

Parece haver controvérsia entre os autores sobre a caracteristica aérea da planta de arroz melhor correlacionada com a profundidade de raízes. Segundo MANBANI \& LAL (1983b), raizes de variedades altas penetram mais profundamente no solo que variedades mais baixas. Já YoSHIDA \& HASEGAWA (1982), numa comparação do sistema radicular de arroz e sorgo, não observou relação entre altura de plantas e profundidade de raízes. Os autores colocam que essa relação é função do perfilhamento, onde plantas com poucos perfilhos tendem a ter um sistema radicular profundo. Há uma correlação negativa entre altura de plantas e número de perfilhos, segundo estes autores. Os resultados deste trabalho indicam que é possível selecionar plantas de estatura baixa com um sistema radicular profundo.

As condições físico-químicas do solo estão correlacionadas ao bom desenvolvimento radicular. Segundo TAYLOR (1980) há uma relação entre o potencial de desenvolvimento do sistema radicular de uma planta e as condições do solo onde ela se encontra; plantas com potencial para sistema radicular profundo apresentam frequentemente em condições de campo sistema radicular superficial, principalmente sob condições adversas do solo. MANBANI \& IAL (1983c) aplicam um método para estimar a distribuição radicular relativa através de um sensor de umidade localizado à diferentes profundidades do solo. Este método baseia-se na relação entre o estado hídrico do solo e a distribuição da densidade radicular no 
perfil do solo, mas é necessário que o solo seja uniforme e a evaporação seja mínima.

TURNER (1986) aponta a importância do ajustamento osmótico na manutenção dos processos produtivos. - ajustamento osmótico de raízes assim como da parte aérea é claramente benéfico.

No trabalho de TURNER et al. (1986a), duas das variedades de sequeiro testadas apresentaram, um menor grau de ajustamento osmótico, provavelmente devido ao menor estresse hídrico.

De acordo com TURNER \& JONES (1980), O ajustamento osmótico é de pouco valor para a planta, exceto para a sobrevivência da mesma, se o organismo não pudesse manter a transpiração pela exploração de um grande volume do solo. Isto ocorre através de uma alta densidade de raízes que continuam a desenvolver-se, devido a manutenção do turgor, e assim podem absorver mais água.

PARICHA \& SAHOO (1975) trabalhando com mutantes de uma variedade resistente à seca, observaram um aumento na relação raíz/parte aérea em todos os tipos de plantas quando o estresse hídrico do solo foi moderado, mas em um estresse severo esta relação foi inconsistente. Segundo JONES et al. (1981), este aumento na relação raíz/parte aérea pode não significar maior habilidade para absorver áqua, já que os déficits hídricos invariavelmente aumentam esta relação, devido a uma perda da parte aérea sem perda de raízes, ou maior perda da parte áerea em relação as raízes.

Plântulas com danos no sistema radicular acima de $50 \%$ de raízes removidas, tem seu rendimento afetado, abaixo deste valor, estas diferenças não são significativas (DAS \& AHMED, 1989). 
Dados obtidos em Los Baños, citados por CHANG et al. (1972) indicam que a maioria das variedades de arroz de sequeiro da África e Filipinas tem, entre outras características: a) frequente enrolamento foliar quando o déficit hídrico começa; b) boa a moderadamente boa resistência à seca, caracterizada por uma produção de raízes profundas e grossas; e c) alta relação raiz/colmo quando a umidade do solo torna-se deficiente.

De acordo com CHANG et al. (1972), a massa seca de raízes por unidade de comprimento do sulco de plantio não parece estar associada com resistência à seca, mas alguns experimentos conduzidos pelo IRAT, citados por MORAIS et al. (1983), mostraram que a massa total das raízes em profundidade constitui-se num parâmetro mais importante para a resistência à seca que o comprimento máximo de raízes. Já o trabalho de JOSHI (1968) mostra diferenças significativas entre comprimento de raízes para as variedadees estudadas, não ocorrendo o mesmo com a característica massa seca total de raízes.

De acordo com CHANG et al. (1972), a altura de plantas de variedades irrigadas tem uma maior redução que a das variedades de sequeiro quando desenvolvidas sob condições de sequeiro.

Em trabalhos do IRRI, citados por DeDATTA et al.(1975), a altura de plantas em diferentes regimes hídricos em relação à altura em plantio em solo saturado foi usada como um indicador de resistência à seca.

De acordo com DeDATTA et al.(1975), plantas sujeitas à estresse hídrico na fase reprodutiva apresentam morte prematura das folhas mais velhas e o murchamento das folhas mais novas, diminuindo a produção de matéria seca. 
Em um trabalho realizado por ALLURI et al. (1982) com variedades de origens diferentes no plantio em sequeiro houve pouca diferença entre a produção de matéria seca até o florescimento, indicando que o desenvolvimento em si não foi limitante para a variedade irrigada (BG90-2).

No trabalho de TURNER et al. (1986a), onde um curto período de déficit hídrico foi imposto (10 dias), não foram observadas diferenças entre as variedadees em cada um dos valores de produção de matéria seca coletados (início e final do estresse).

No trabalho realizado por JOSHI (1968), onde o período de estresse foi maior, as variedades resistentes à seca são caracterizadas por um alto peso médio da matéria seca da parte aérea no final do estresse.

- grau de exposição da panícula em relação à folha bandeira varia de uma variedade para outra e isto pode influenciar a fertilidade das espiguetas.

Segundo O'TOOLE \& NAMUCO (1983) e CRUZ \& O'TOOLE (1984), a alta esterilidade das espiguetas está associada a uma pobre inserção de panículas. A pobre inserção de panícula afeta diretamente o enchimento e o rendimento dos grãos por causar a esterilidade das espiguetas mais baixas, as quais permanecem dentro da bainha da folha (ALLURI et al., 1982). Entretanto, observações de campo sugerem que é possivel selecionar para boa inserção entre plantas semi-anãs.

Segundo ARRAUDEAU \& VERGARA (1988), a ocorrência de déficit hídrico durante o estágio de formação da panícula pode causar aborto das espiguetas, chegando a 100\% de esterilidade dependendo da severidade do déficit. o atraso no florescimento, ou envolvimento de plasticidade em resposta ao déficit hídrico, é uma 
característica de escape à seca (ARRAUDEAU, 1989; INGRAM et al., 1990), e pode diminuir as perdas no rendimento.

Em trabalhos conduzidos por PINHEIRO (1989), as panículas que não foram emitidas durante um ciclo de estresse, apresentaram maior fertilidade das espiguetas. Foi concluido que o retardamento do alongamento da panícula pode atenuar os efeitos da deficiência hídrica caso a deficiência hídrica não seja muito prolongada.

\subsection{Melhoramento visando resistência à seca}

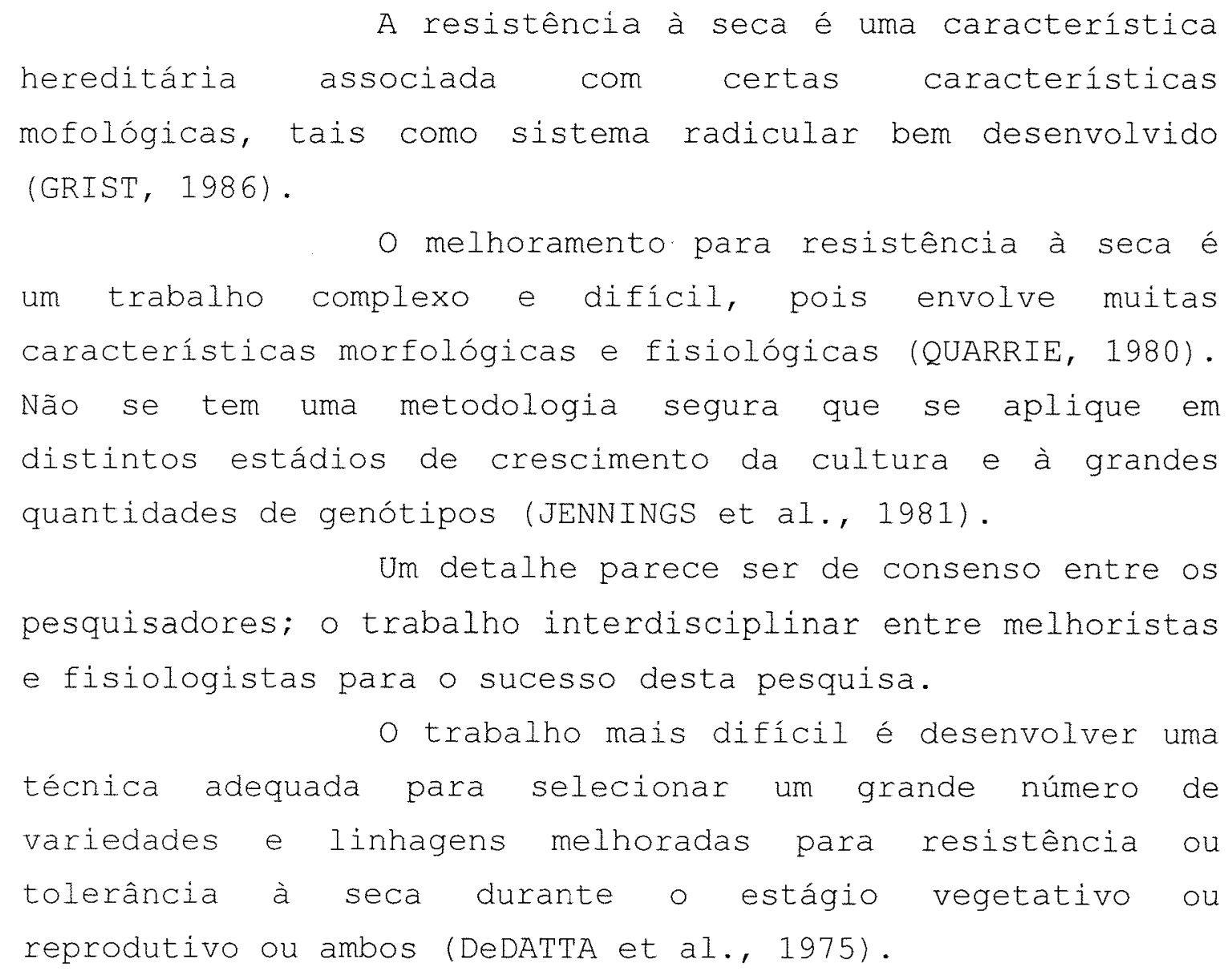


Vários autores demonstraram métodos para avaliar e melhorar genótipos de arroz para a resistência à seca.

$$
\text { LORESTO et al. (1976) e LORESTO \& CHANG }
$$
(1981) estabeleceram uma escala de avaliação da resistência à seca na fase vegetativa e reprodutiva, além de uma escala para avaliar a recuperação dos genótipos após a normalização do suprimento hídrico. Na escala de avaliação da fase reprodutiva, são consideradas as seguintes características: atraso do florescimento (genótipo em condições de estresse em relação a um plantio em condições normais de suprimento hídrico); esterilidade de espiguetas; emissão de panículas e - enrolamento foliar. A avaliação é feita plantando-se os genótipos na estação seca, com e sem irrigação suplementar. Numa avaliação de resistência à seca feita por estes autores, a maior proporção de variedades resistentes foi encontrada entre as variedades tradicionais de sequeiro da África, seguida pelas variedades da América do Sul e Laos.

\section{O'TOOLE \& CHANG (1979) também avaliaram} caracteristicas de resistência à seca de genótipos, comparando o plantio em sequeiro, com ou sem suplementação hídrica. O rendimento proporcional em relação ao campo irrigado, também é um critério utilizado pelos autores. CHANG et al. (1982) também utilizaram a redução relativa no rendimento devido ao estresse hídrico para calcular a relação entre resistência à seca e performance no rendimento.

De acordo com observações de CHANG et al. (1972), as seguintes características elevarão o potencial de rendimento de variedades desenvolvidas sob o cultivo de sequeiro sujeito à deficit hídrico: 1) vigor vegetativo 
precoce e folhas moderadamente longas e ligeiramente decumbentes para proporcionar cobertura do solo e facilitar - enrolamento foliar quando a umidade do solo tornar-se deficiente; 2) um vigoroso sistema radicular capaz de desenvolver raízes profundas e grossas quando o suprimento hídrico diminui próximo à superfície do solo.

A seleção durante a estação úmida é altamente sujeita a variações do tempo, enquanto os testes na estação seca não revelam o potencial agronômico na estação úmida (CHANG \& LORESTO, 1986). Assim, procura-se avaliar a resistência à seca e planta-se também na estação úmida para avaliar as características agronômicas dos genótipos.

Apesar da avaliação visual de certas características ser condenada por alguns autores (TURNER et al., 1986a), é o tipo de avaliação que permite analisar um grande número de entradas na estação seca. E segundo CHANG \& LORESTO (1986), de acordo com alguns trabalhos (CHANG et al., 1982; O'TOOLE \& CHANG, 1979), os dados da estação seca mostram alta correlação com as reações da estação úmida quando um estresse prolongado ocorre nesta estação.

GOMATHINAYAGAM et al. (1988) trabalharam com um método desenvolvido em vasos, baseado no protocolo do IRRI para seleção à seca em campo e para tolerância à seca sob desenvolvimento radicular em profundidade limitada. Os autores concluiram que os melhores parâmetros para estudar caracteristicas fisiológicas ou de crescimento são: peso da matéria seca de raízes e da parte aérea; potencial hídrico foliar e área foliar, embora sejam fortemente relacionados com resistência à seca, requerem equipamentos mais dispendiosos. No período estudado do estresse (45 dias após a semeadura) o parâmetro comprimento de raízes não 
discrimina bem os genótipos, e a altura de planta não se correlaciona com nenhum outro parâmetro. Este método apresenta a desvantagem de não se poder trabalhar com muitos genótipos.

De acordo com SWINDALE \& BIDINGER (1981), - melhoramento de plantas para resistência à seca têm três opções, cada qual com certas vantagens, embora, segundo os autores, nenhuma proporcione uma resposta completa. Estas opções são comentadas a seguir:

1) selecionando para a estabilidade do rendimento em locais e anos secos. Este procedimento utiliza o estresse natural do ambiente como critério de seleção;

2) selecionando diretamente para performance em déficit hídrico controlado. Este método é baseado na seleção para resistência à insetos e doenças na qual as linhas são expostas à uma pressão uniforme, severa e repetitiva, permitindo às linhas resistentes serem identificadas com um alto grau de acerto.

3) selecionando para características fisiológicas e bioquímicas diretamente relacionadas para resistência à seca em campo. Este método, segundo os autores, é, teoricamente, mais rápido e efetivo que os outros métodos propostos.

Estas características já foram citadas anteriormente no ítem "características da planta em resposta ao déficit hídrico", em particular o sistema radicular e a resistência radicular; controle estomatal; manutenção do potencial hídrico foliar e tolerância ao dessecamento.

Segundo SWINDALE \& BIDINGER (1981), para cada uma destas características há uma relação com a performance diferencial da variedade em pelo menos uma condição de estresse. 
Com relação às características do sistema radicular, vários estudos da variabilidade genética destas vem sendo realizadas em várias culturas, inclusive o arroz (JORDAN \& MILLER, 1980; AHMADI, 1983; DERERA et al., 1969; ARMENTA-SOTO et al., 1983; EKANAYAKE et al., 1985). Este estudo torna-se importante no melhoramento genético de variedades para a resistência à seca.

Segundo TOWNLEY-SMITH \& HURD (1979) e CHANG \& LORESTO (1986), vários trabalhos relatam uma associação entre o desenvolvimento inicial das raízes e a quantidade de raízes na maturidade em algumas culturas. Assim, uma seleção de plantas para um maior desenvolvimento radicular poderia ser feita na fase de plântulas.

A seleção através das características fisiológicas e bioquímicas citadas, seria o método mais simples, mas deve-se tomar todo cuidado para que estas características realmente levem a uma resistência de campo a seca.

CHANG et al. (1986) utilizaram vários experimentos e técnicas para pesquisar o controle genético das características dos componentes que contribuem para 0 escape e a evasão à seca, e a relação genética entre três variedades de arroz. Encontraram resultados interessantes com relação à herança de cada característica e a possibilidade de recombinar as desejáveis.

De acordo com BLUM (1982), realmente há uma variação genética nas várias características de adaptação à seca, entretanto, este volume de informações pode ser de limitado valor para os trabalhos de melhoramento devido: 1) enquanto a variação genética de uma dada característica pode ser indicada por uma metodologia fisiológica exata mas morosa, o seu uso em trabalhos de 
rotina para seleção em massa pode ser inviável; e 2) há falta de informações em relação a dadas características fisiológicas adaptadas à seca e rendimentos econômicos dentro de ambientes definidos estressados e não estressados.

De acordo com BOYER \& MCPHERSON (1976), melhorando uma planta para menor inibição do alongamento celular, menor senescência de folhas e melhor sistema radicular durante uma seca prolongada, pode-se melhorar a produtividade de plantas sob condições moderadas de seca, particularmente em cereais cultivados. Os autores enfatizam, entretanto, que qualquer seleção para esses caracteres devem ser acompanhados por extensivos testes de campo.

CHANG \& LORESTO (1986) sugerem várias técnicas de seleção para resistência à seca. São elas: a) seleção massal: teste feito em campo em presença e ausência de déficit hídrico; b) topossequência: baseia-se no plantio dos genótipos em campo em área de diferentes profundidades do lençol freático; c) técnica "line-source spinkler" (linha central de aspersores): os genótipos são irrigados por uma Iinha de aspersores onde forma-se um gradiente de umidade; d) testes de tolerância ao dessecamento: consiste em medir o grau de enrolamento foliar, morte das folhas e perda de clorofila (cor verde) em plantas estressadas (tensão do solo de 16 bars ou mais). A cor verde normal retorna às folhas das variedades tolerantes após 12 horas de retorno da água; e) seleção para um sistema radicular profundo: são várias técnicas citadas, entre elas algumas já descritas aqui; f) métodos de avaliação suplementar: nível constante do lençol freático, características foliares e radiculares afetando a evapotranspiração; temperatura da copa da cultura; redução relativa de rendimento sob estresse; e regulação osmótica. 
Estes métodos podem auxiliar outras avaliações complexas da tolerância à seca nos genótipos em seleção.

Uma das estratégias de seleção proposta por ARRAUDEAU (1989), considera o potencial do rendimento como uma característica irrelevante já que as condições ótimas de desenvolvimento não existem. Neste caso, a principal vantagem é a estabilidade do rendimento, e a principal desvantagem é que a seleção para rendimento é pouco eficiente, já que a herdabilidade é relativamente baixa para o rendimento e os componentes deste, sob condições de estresse. Mas este mesmo autor cita que, em trabalhos do IRRI em 1988, uma progênie avançada, altamente resistente à seca, mostrou também um alto potencial de rendimento.

De acordo com CHANG et al. (1982), um alto nível de resistência de campo à seca foi associado com baixa habilidade para o perfilhamento, alta estatura, raízes grossas e profundas, ampla plasticidade em enrolar e desenrolar as folhas, total desenvolvimento ininterrupto do grão sob estresse hídrico - um complexo de características geralmente encontradas nas variedades de sequeiro tradicionais do Sudeste Asiático. A habilidade da planta em recuperar-se após a seca foi associada com alta habilidade para o perfilhamento, baixa plasticidade em enrolar e desenrolar as folhas, tolerância ao dessecamento, atraso no florescimento, decréscimo no tamanho e peso dos grãos sob déficit hídrico - manifestações comuns em variedadees tradicionais de arroz irrigado e semi-anãs com altos rendimentos.

Apesar dos vários trabalhos que vêm sendo realizados, a resistência à seca na fase vegetativa é mais facilmente encontrada que na fase reprodutiva. Poucas 
variedades ou linhagens melhoradas apresentam alta resistência à seca no estágio reprodutivo (CHANG et al., 1982), o maior número são de genótipos resistentes no estágio vegetativo (DeDATTA \& SESHU, 1982).

ALLURI et al. (1982) relatam que pesquisas do IITA para identificar um ideotipo para sequeiro indicaram que a performance das semi-anãs em condições de sequeiro é uma característica específica à variedade, e não uma característica geral de tipo de planta. Assim, o tipo de planta semi-anã em si, não seria uma limitação para cultivos em condições de sequeiro. As semi-anãs de sequeiro diferem das semi-anãs irrigadas por terem número moderado de panículas $\left(150-200 / \mathrm{m}^{2}\right)$, raízes mais espessas, folhas mais baixas decumbentes, folhas superiores eretas e, sob seca, panículas com boa inserção e bom enchimento de grãos.

o melhoramento para resistência à seca deve levar em consideração um completo conhecimento do tipo de déficit hídrico que ocorre no ambiente em questão e da grande variabilidade das adaptações morfológicas do genótipo estudado. 


\section{MATERIAL E MÉTODOS}

- trabalho foi conduzido no centro Nacional de Pesquisa de Arroz e Feijão (CNPAF), da Empresa Brasileira de Pesquisa Agropecuária (EMBRAPA), localizado na Fazenda Capivara, município de Goianira, em Goiás, cujas coordenadas geográficas são: latitude $16^{\circ} 41^{\prime} \mathrm{S}$, longitude $49^{\circ} 17^{\prime} \mathrm{W}$ e altitude de $729 \mathrm{~m}$, em solo classificado como Latossolo Vermelho-Escuro distrófico.

\subsection{Condução do ensaio no campo}

Eoram conduzidos, simultaneamente, dois experimentos de campo em um delineamento experimental de blocos balanceados em grupos (GOMEZ \& GOMEZ, 1984), com três repetições. Cada grupo foi composto por dezoito variedades, selecionadas a partir de uma origem comum, a seguir caracterizada:

Grupo de arroz irrigado: composto por variedades provenientes de programas de melhoramento conduzidos pelo Centro Nacional de Pesquisa de Arroz e 
Feijão (CNPAF), Centro Internacional de Agricultura Tropical (CIAT) e Instituto Agronômico de Campinas (IAC). Essas variedades apresentam certas caracteristicas morfológicas em comum descritas por FONSECA et al. (1984): colmo curto e resistente, folhas pequenas, estreitas e bem eretas, boa capacidade de perfilhamento. De acordo com a classificação de GLAZMANN (1986), variedades com estas características pertencem ao grupo indica (Grupo I).

\section{Grupo de arroz de sequeiro tradicional:}

são variedades de origem desconhecida, provenientes de coletas regionais. As variedades tradicionais de arroz de sequeiro em geral são de porte alto, tem folhas longas e largas, decumbentes, poucos perfilhos e baixa relação grão/palha. Tem sistema radicular profundo e desenvolvido, com alta proporção de raízes grossas e longas. Na classificação de GLAZMANN (1986), variedades com estas características pertencem ao grupo japonica (Grupo VI).

\section{Grupo de arroz de sequeiro melhorado}

africano: composto por variedades criadas pelo programa de melhoramento do centre Internationale en Recherche Agronomique pour le Dévelopment (CIRAD) na África. Normalmente são plantas de perfilhamento moderado, eretas, com boa inserção da panícula, e que apresentam moderada resistência à seca (IRAT/CIRAD, 1989). Na classificação de GLAZMANN (1986), estas variedades pertencem ao grupo japonica (Grupo VI).

\section{Grupo de arroz de sequeiro melhorado}

brasileiro: composto por variedades provenientes dos programas de melhoramento do CNPAF, IAC e Empresas Estaduais de Pesquisa. Estes materiais possuem caracteristicas morfológicas semelhantes ao sequeiro nacional regional, mas 
apresentam algumas características melhoradas através de seleções. São elas: maior resistência à doenças, maior resistência ao acamamento resultante de colmos mais resistentes, maior número de perfilhos e maior produtividade.

\section{Grupo de arroz de sequeiro favorecido:}

variedades provenientes do programa de melhoramento do CNPAE; são materiais adaptados às condições mais favoráveis de plantio, ou seja, onde a água e nutrientes do solo não são fatores limitantes. Estes materiais possuem estatura intermediária e maior número de perfilhos do que o arroz de sequeiro melhorado. No geral, possuem caracteristicas intermediárias entre o arroz irrigado e o de sequeiro, pois são resultado de cruzamento entre os grupos indica e japonica.

A relação das variedadees/linhagens de cada grupo está na Tabela 09 (Apêndice).

Com base na definição do período crítico, foram selecionados para o estudo genótipos de ciclo similar, para que a avaliação do comportamento perante a seca excluisse a reação de escape à seca. Esta seleção foi feita com base nos dados de florescimento de ensaios do CNPAE conduzidos em anos anteriores, buscando que a variação não excedesse de oito dias.

A instalação dos experimentos foi realizada em 06/02/92, tardiamente em relação à época recomendada para plantio, visando coincidir o período reprodutivo dos genótipos em teste com o início da estação seca na região.

O solo apresentava originalmente um $\mathrm{pH}$ em torno de 5.5, baixo conteúdo de fósforo, potássio e matéria 
orgânica, caracterizando um solo típico de cerrado. Foi preparado por meio de uma aração profunda com arado de aiveca e passagem posterior de uma grade niveladora.

A adubação fornecida foi de $350 \mathrm{~kg} / \mathrm{ha}$ da fórmula 4-30-16 + zinco e $30 \mathrm{~kg} / \mathrm{ha}$ de FTE Br12 no plantio. Em cobertura foram aplicados $38 \mathrm{~kg} / \mathrm{ha}$ de Nitrogênio por ocasião da diferenciação do primórdio floral.

A densidade de semeadura foi de oitenta sementes por metro linear e cada parcela foi constituída por três sulcos de 2,7 m espaçados de 0,5 m, totalizando 270 parcelas de $1,5 \times 2,7 \mathrm{~m}$ em cada experimento.

Foram aplicados Pyruquilon no tratamento de sementes, para o controle da brusone, e Carbofuram 5\% no sulco de plantio, para controle de insetos do solo.

Quando a precipitação não foi eficiente, os dois experimentos receberam irrigação suplementar por aspersão até 78 dias após a semeadura. Decorrido este período, a irrigação suplementar foi suspensa em um dos experimentos. Como as chuvas cessaram quase que completamente, permitiu-se a indução de deficiência hídrica às plantas. Essa situação foi mantida por 25 dias, após os quais o experimento estressado voltou a receber irrigação de forma a manter também as plantas bem supridas de água até a maturidade. Durante o período de indução de deficiência hídrica no primeiro experimento (Exp.I), o segundo recebeu sete irrigações da ordem de $30 \mathrm{~mm}$ cada, sendo utilizado como controle irrigado (Exp.II).

\subsection{Parâmetros avaliados}

A seleção dos parâmetros a serem avaliados, foi função das características que envolvem a 
avaliação de resistência à seca recomendada por LORESTO \& CHANG (1981) e LORESTO et al (1976), e outras necessárias ao entendimento de possíveis relações com o comportamento dos materiais avaliados citados por outros autores (CHANG \& LORESTO, 1986).

\subsubsection{Conteúdo relativo de água no solo}

- conteúdo relativo de água no solo foi determinado em cinco ocasiões durante a imposição da deficiência hídrica através do método gravimétrico, até a profundidade de $60 \mathrm{~cm}$, a incrementos de $20 \mathrm{~cm}$ em sete posições em cada uma das repetições, no dois experimentos. A última coleta foi feita em dez posições em cada repetição dentro do Exp.I e em cinco posições em cada repetição no Exp.II.

\subsubsection{Secamento foliar}

- secamento de folhas foi quantificado através da seguinte escala visual (CIAT, 1983):

1 - Planta sadia, com apenas ligeiro secamento apical das folhas.

2 - Secamento apical na maioria das folhas até um quarto de seu tamanho.

3 - Todas as folhas com um quarto a metade da sua área foliar completamente seca.

4 - Mais de dois terços do total das folhas completamente secas.

$$
5 \text { - Todas as plantas secas. }
$$


Após o início do déficit hídrico foram dadas notas de secamento em cinco datas diferentes até o final deste, sempre no período da manhã.

\subsubsection{Enrolamento foliar}

o enrolamento de folhas foi quantificado através de escala visual apresentada a seguir (O'TOOLE \& MOYA, 1978):

$$
\begin{aligned}
& 1 \text { - sem enrolamento } \\
& 2 \text { - folha sai da linha reta } \\
& 3 \text { - folha com bordas curvadas } \\
& 4 \text { - folha enrolada, planta ereta } \\
& 5 \text { - folha enrolada, planta }
\end{aligned}
$$

acamando (sem turgescência).

Após o início do déficit foram dadas notas de enrolamento, sempre no período da manhã (8:00-10:00h), em seis datas diferentes até o final do déficit hídrico.

\subsubsection{Florescimento}

- florescimento foi considerado como a data em que as parcelas apresentavam $50 \%$ das panículas emitidas. Essa anotação permite quantificar o atraso da floração no experimento submetido à deficiência hídrica em relação ao controle irrigado. 


\title{
3.2.5. Altura
}

A altura foi determinada na maturidade, medindo-se cinco plantas por parcela, tomadas aleatoriamente, da superfície do solo até o final da panícula. Utilizou-se a média de altura das cinco plantas.

\subsubsection{Percentual de exposição da panícula}

- percentual de exposição da panícula foi medido por ocasião da colheita em dez panículas coletadas na área útil de cada parcela. Para tanto foram determinados o comprimento da porção exposta da panícula (CExp), medida do colar da folha bandeira à ponta da panícula, e o comprimento total da panícula (CPan), qual seja, do primeiro entrenó da planta até a ponta da panícula. Estas medidas foram feitas em laboratório com auxílio de régua milimetrada. o percentual de exposição (oExp) foi calculado pela seguinte fórmula (O'TOOLE \& NAMUCO, 1983):

$$
\frac{\circ}{\circ} \operatorname{Exp}=(\operatorname{Cexp} / \operatorname{Cpan}) 100
$$

\subsubsection{Fertilidade de espiguetas}

\begin{abstract}
Para a estimativa deste parâmetro foram usadas as mesmas dez panículas em que foi medido o percentual de exposição. Após serem debulhadas, foram separados os grãos vazios dos grãos cheios, e estimada visualmente a percentagem de fertilidade em cada parcela. Segundo GARRITY \& O'TOOLE (1994), a correlação da
\end{abstract}


fertilidade de espiguetas estimada através da contagem de grãos cheios e vazios e da estimada visualmente é altamente significativa $(R=0.93 * *)$.

\subsubsection{Biomassa total na fase reprodutiva}

A determinação deste parâmetro foi feita através de amostragem em cada grupo, coletando-se quatro amostras de 0,30 metros lineares, perfazendo 0,15 metros quadrados por amostra, por ocasião do florescimento.

Imediatamente após a coleta no campo, as amostras foram acondicionadas em sacos de papel e levadas para uma estufa de circulação forçada a $70^{\circ} \mathrm{C}$ até peso constante ( 48 horas). Após este período, foram pesadas em balança digital com precisão de duas casas decimais $(0,01 \mathrm{~g})$.

\subsubsection{Potencial hídrico em folhas ao meio dia}

As medidas do potencial hídrico de folhas (¥), visando caracterizar a intensidade da deficiência hídrica, foram realizadas das $12: 30$ às 14:30h (meio do dia), utilizando-se uma câmara de pressão portátil (SCHOLANDER et al., 1965).

Devido a impossibilidade de quantificar o $¥$ ¥ em todas as parcelas, optou-se por amostrar dez folhas por grupo colhidas aleatoriamente, limitando a amostragem à segunda folha completamente expandida. As folhas selecionadas foram protegidas da perda de água envolvendo-as 
em um envelope duplo de papel alumínio (JONES, 1979; O'TOOLE \& MOYA, 1981); e seccionadas com uma lâmina de barbear na altura do colar (porção espessa da folha situada entre a lâmina e a bainha). Eoram colocadas em caixa de isopor com gelo para o transporte até a câmara de pressão, normalmente situada no meio do experimento. As amostras foram então afixadas uma de cada vez a um suporte de amostras e colocadas hermeticamente em uma câmara de pressão, modelo 3005 da Soil Moisture Corp., ficando exposto ao ambiente apenas um pequeno segmento da folha do lado da superfície seccionada. Ar comprimido foi então introduzido lentamente no compartimento da câmara e, através de uma lupa manual, observou-se o aparecimento da primeira gotícula na superfície cortada. Neste momento o fluxo de ar foi cortado e então fez-se a leitura da pressão aplicada no manômetro do aparelho. Esta metodologia baseou-se na técnica desenvolvida por SCHOLANDER et al. (1965).

\subsubsection{Rendimento de grãos}

Eoram colhidos dois metros da linha central de cada parcela tomando-se o cuidado de descartar $0,35 \mathrm{~m}$ de cada extremidade da linha. Os grãos foram separados da palha e pesados em balança digital com precisão de $0.01 \mathrm{~g}$, e sua umidade determinada em medidor do tipo DOLE 400. A massa dos grãos das panículas colhidas para medir a emissão e a fertilidade das espiguetas foi somada à massa de grãos na colheita. O rendimento em gramas por metro quadrado de cada parcela foi convertido para 13\% de umidade.

Foram realizadas as análises de variância para os parâmetros estudados de acordo com o recomendado por 
GOMEZ \& GOMEZ (1984) para O delineamento experimental utilizado. As médias dos grupos foram comparadas através do teste de Tukey a 5\% de significância.

o efeito do regime hídrico foi estimado através da análise conjunta dos experimentos (Exp.I e Exp.II) .

Foram calculados os coeficientes de correlação linear simples para o rendimento e as outras variáveis, e a nota global de seca e as variáveis que a compuseram. 


\section{RESULTADOS E DISCUSSÃO}

4.1. Caracterização da intensidade da deficiência hídrica

Decorridos 78 dias após o plantio, as chuvas cessaram quase que completamente. A Figura 1. mostra a precipitação durante o período de imposição da deficiência hídrica.

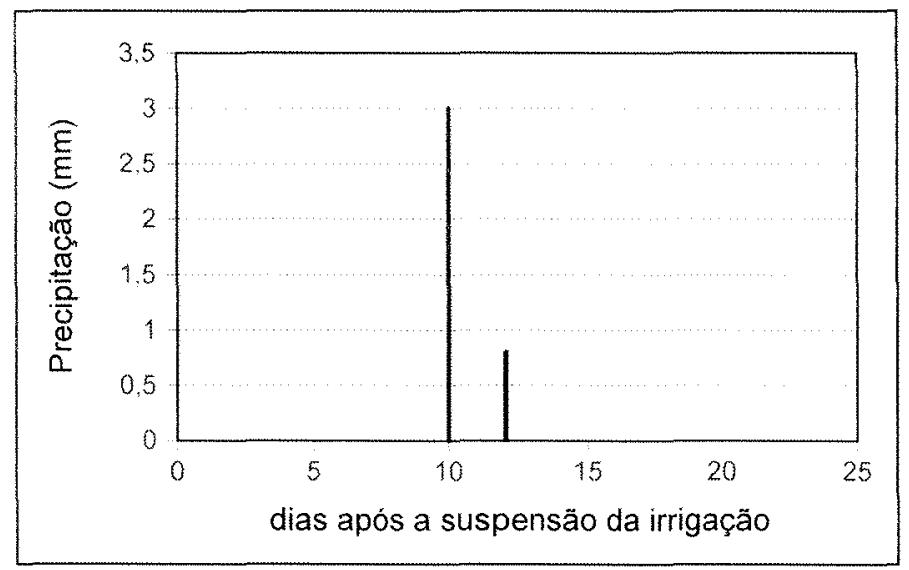

Figura 1. Precipitação durante o período de imposição da deficiência hídrica no Exp.I 
Aos seis dias após a suspensão da irrigação, o Exp.I já apresentava um menor teor de água no solo em relação ao controle irrigado. Isto resultou em um estabelecimento de deficiência hídrica às plantas no Exp.I, evidenciado na Figura 2B, através das medidas do potencial da água das folhas.

A suspensão da irrigação pelo período de 25 dias no estágio reprodutivo foi capaz de induzir um déficit hídrico de adequada intensidade aos grupos de variedades em avaliação. O potencial da água atingiu média de $-1.8 \mathrm{MPa}$ no experimento que sofreu deficiência hídrica, ultrapassando o valor de $-1.7 \mathrm{MPa}$ considerado por O'TOOLE \& MOYA (1981) como crítico e indicativo de déficit hídrico na planta. Os trabalhos de TURNER et al.(1986a);BOYER \& MCPHERSON(1976); VIEIRA et al.(1991) e O'TOOLE \& CRUZ (1980), também indicam valores similares.

Sabe-se que o estágio de desenvolvimento da planta desempenha papel fundamental na sua reação à seca. o período mais crítico do ciclo de desenvolvimento da planta de arroz é a sua fase reprodutiva (BOYER \& MCPHERSON, 1976; O'TOOLE \& MOYA, 1981; EMBRAPA, 1984). A fase de floração e a gametogênese, que ocorre aproximadamente 11 dias antes da floração, representam os períodos mais críticos do estágio reprodutivo (Matsushima, 1962, citado por YOSHIDA, 1975 e O'TOOLE, 1982). Quando a deficiência hídrica ocorre nestas fases, as perdas no rendimento são altas.

Apesar do cuidado em selecionar variedades de arroz com o mesmo ciclo, houve uma variação maior do que oito dias na data do florescimento dos genótipos do controle 

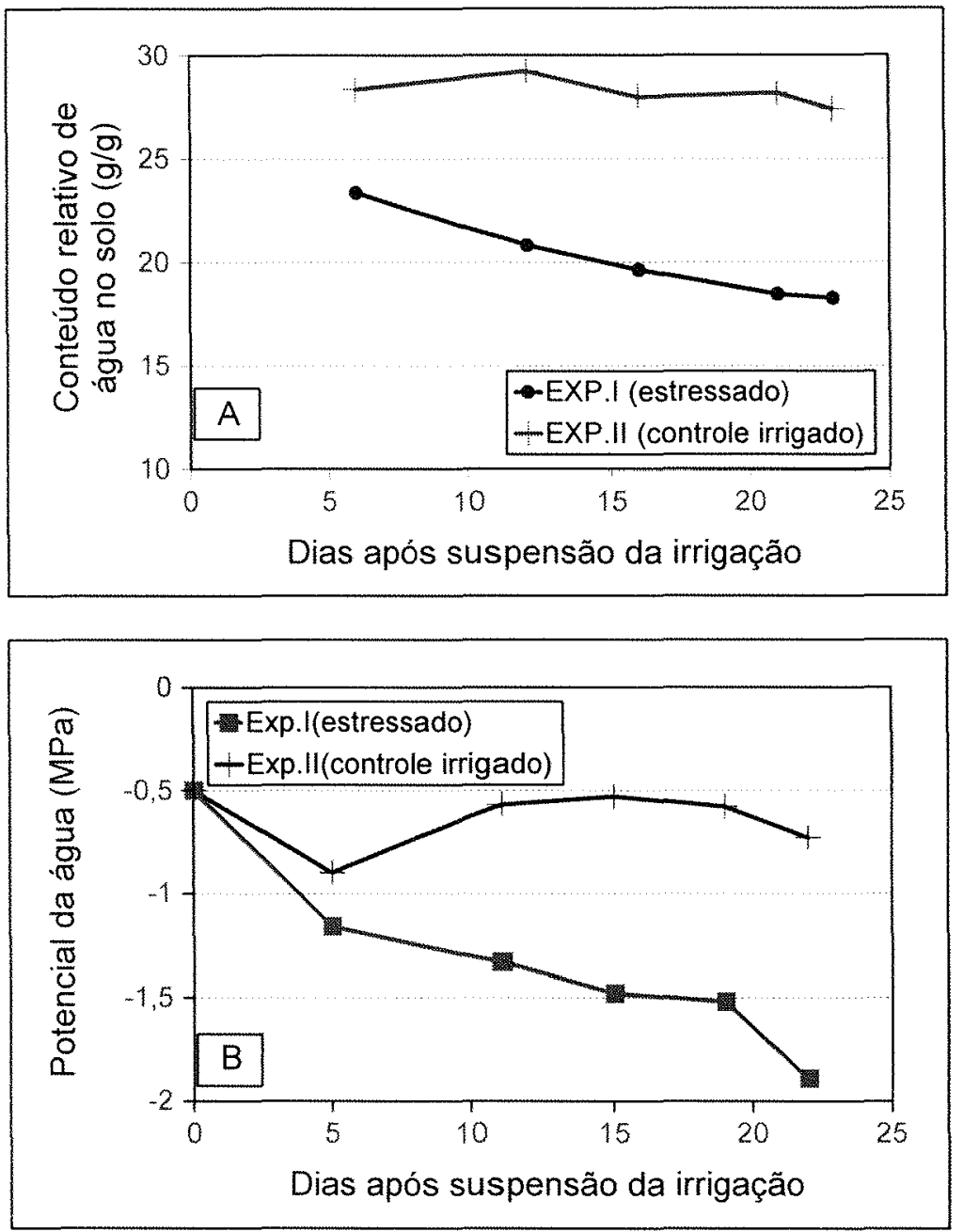

Eigura 2. Conteúdo relativo de água no solo no Exp.I e Exp.II até $60 \mathrm{~cm}$ de profundidade durante 0 período de imposição dos regimes hídricos(A) e Valores médios do potencial da água da folha (média geral) ao longo do tempo no Exp.I e $\operatorname{Exp}$. II (B)

irrigado, seja entre ou dentre grupos, como pode ser observado na Eigura 3. Isto deveu-se, provavelmente, à data do plantio realizado tardiamente na estação de cultivo para ampliar a chance de ocorrência do déficit hídrico. Mas a maioria das variedades dentro de cada grupo teve as fases críticas de florescimento ou de gametogênese, que ocorre aproximadamente quinze dias antes do florescimento, 
ocorrendo dentro do período de imposição da deficiência hídrica.

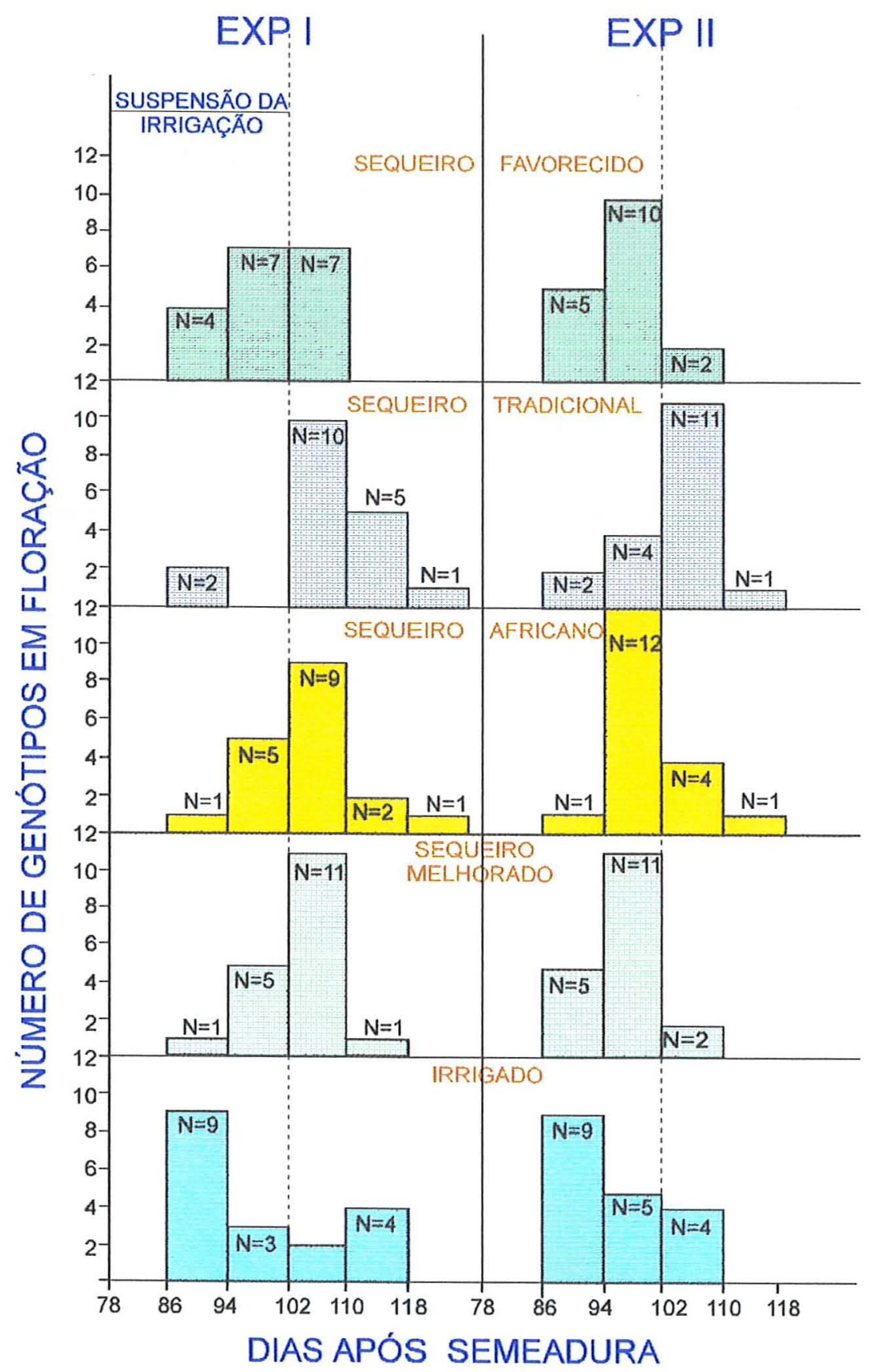

Figura 3. Distribuição da data de floração das variedades dentro de cada grupo, nos dois regimes hídricos (Exp.I e Exp.II), Considerando períodos de 8 dias.

$\mathrm{N}=$ número de variedades 
Ainda na Figura 3., observa-se variação da distribuição do florescimento do Exp.I em relação ao Exp.II, o que será abordado posteriormente.

\subsection{Efeito da deficiência hídrica sobre os parâmetros avaliados}

A análise conjunta dos dois experimentos detectou um efeito muito pronunciado da deficiência hídrica sobre o rendimento e todos os parâmetros de avaliação da resistência à seca, conforme pode ser verificado na Tabela 1 .

Apesar das significativas diferenças entre grupos, estes não apresentaram um comportamento diferencial em resposta à seca no que se refere ao rendimento, fertilidade de espiguetas, altura de plantas e biomassa. contudo, para os parâmetros percentagem de exposição de panículas, enrolamento foliar, secamento, número de dias até - florescimento e potencial da água, a interação regime hídrico x grupos foi altamente significativa (Tabela 1). 
Tabela 1. Quadrados médios para os vários parâmetros medidos no Exp.I e Exp.II, em análise conjunta.

\begin{tabular}{|c|c|c|c|c|}
\hline \multirow[t]{2}{*}{ Variáveis } & \multicolumn{3}{|c|}{ Quadrados médios } & \multirow{2}{*}{$\begin{array}{c}\text { C.V. } \\
\left(\frac{\circ}{6}\right)\end{array}$} \\
\hline & RH & GRUPO & RH*GRUPO & \\
\hline Produção (Kg/ha) & $3837738.96 * *$ & $81947.56^{* *}$ & 7446.01 n.s. & 26.60 \\
\hline $\begin{array}{ll}\text { Fertilidade } & \text { de } \\
\text { espiguetas }(\%) & \end{array}$ & $117956.22 * *$ & $12281.11^{* *}$ & 335.78 n.s. & 23.57 \\
\hline $\begin{array}{ll}\text { Emissão } & \text { de } \\
\text { panículas }(\%) & \end{array}$ & $1.3168^{* *}$ & $0.3571 * *$ & $0.0371 * *$ & 6.33 \\
\hline Altura $(\mathrm{cm})$ & $13.944 .60 * *$ & $23979.02 * *$ & 105.04 n.s. & 6.02 \\
\hline Biomassa $\left(\mathrm{g} / \mathrm{m}_{2}\right)$ & $11.986 .41 * *$ & 15661.59 n.s. & 21862.99 n.s. & 22.23 \\
\hline $\begin{array}{l}\text { Enrolamento Foliar } \\
(1-5)\end{array}$ & $385.07^{* *}$ & $2.79 * *$ & $1.55^{* *}$ & 16.95 \\
\hline $\begin{array}{l}\text { Secamento Foliar } \\
(1-5)\end{array}$ & $70.42 * *$ & $4.11^{*}$ & $4.11 *$ & 21.48 \\
\hline Floração (dias) & $1667.78 * *$ & $1272.61^{* *}$ & $50.15 * *$ & 2.47 \\
\hline $\begin{array}{l}\text { Potencial Hídrico } \\
\text { (PH6) }\end{array}$ & $10043.34 * *$ & $86.92 * *$ & $54.19 * *$ & 11.94 \\
\hline
\end{tabular}

*, ** Significativo a $1 \%$ e $5 \%$ de probabilidade, respectivamente.

\subsubsection{Florescimento}

Em complemento ao já observado na Figura 3, a Figura 4 apresenta o florescimento médio dos grupos de genótipos nos dois experimentos, e a porcentagem do atraso no florescimento do Exp.I em relação ao Exp.II. Conclui-se que os grupos de sequeiro tradicional, melhorado e africano apresentaram um maior atraso no florescimento por efeito da deficiência hídrica, em comparação com os grupos de sequeiro favorecido e irrigado. O atraso no florescimento, ou desenvolvimento de plasticidade em resposta ao déficit hídrico, é considerado como uma característica de escape à seca (ARRAUDEAU, 1989; INGRAM et al., 1990). Este atraso pode levar à menores perdas no rendimento, nos casos em que seja possível um retorno das condições favoráveis.

Segundo PINHEIRO (1989), a capacidade da planta de arroz de escalonar a emergência de suas panículas, 
pode proporcionar maior chance à planta de encontrar condições favoráveis, pelo menos para parte de seus perfilhos, assegurando dessa forma alguma produção de sementes.
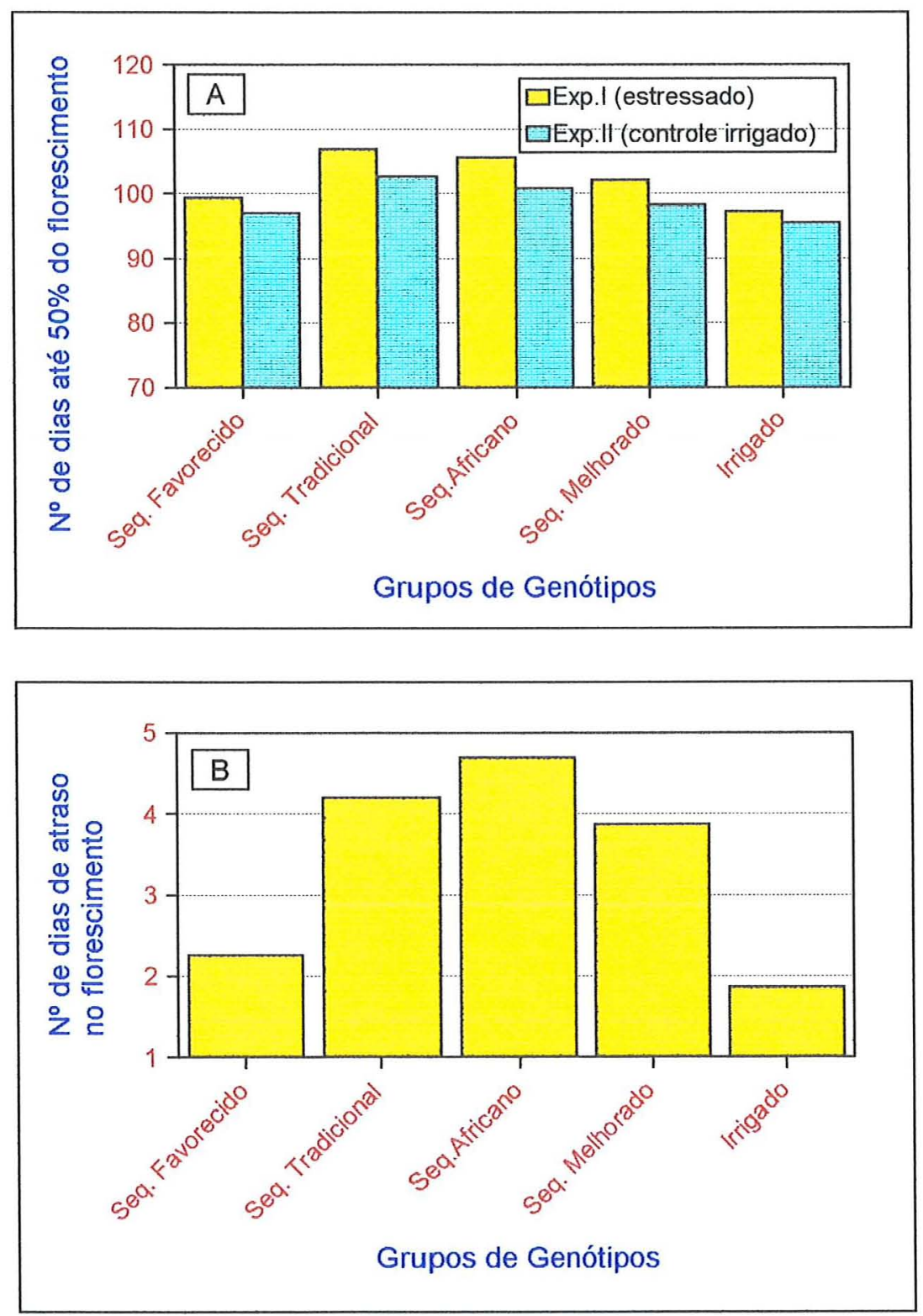

Figura 4. Número de dias até 50\% do florescimento nos Grupos de Genótipos no Exp.I e Exp.II (A) e número de dias de atraso do florescimento no experimento sob deficiência hídrica em relação ao controle irrigado (B). D.M.S.1 $=1.61$ (Exp.I), D.M.S.2 $=1.30$ (Exp.I): D.M.S(diferença mínima significativa) 


\subsubsection{Estado hídrico da planta}

De acordo com a Figura 5 e a Tabela 3, os grupos de genótipos apresentaram diferenças no potencial da água no meio do dia desde o início das medições. Contudo essas diferenças tornaram-se consistentes apenas no $19^{\circ}$ dia, em que o grupo de arroz irrigado diferenciou-se dos demais por apresentar o menor potencial da água da folha, enquanto - sequeiro africano apresentou o maior valor desse parâmetro.

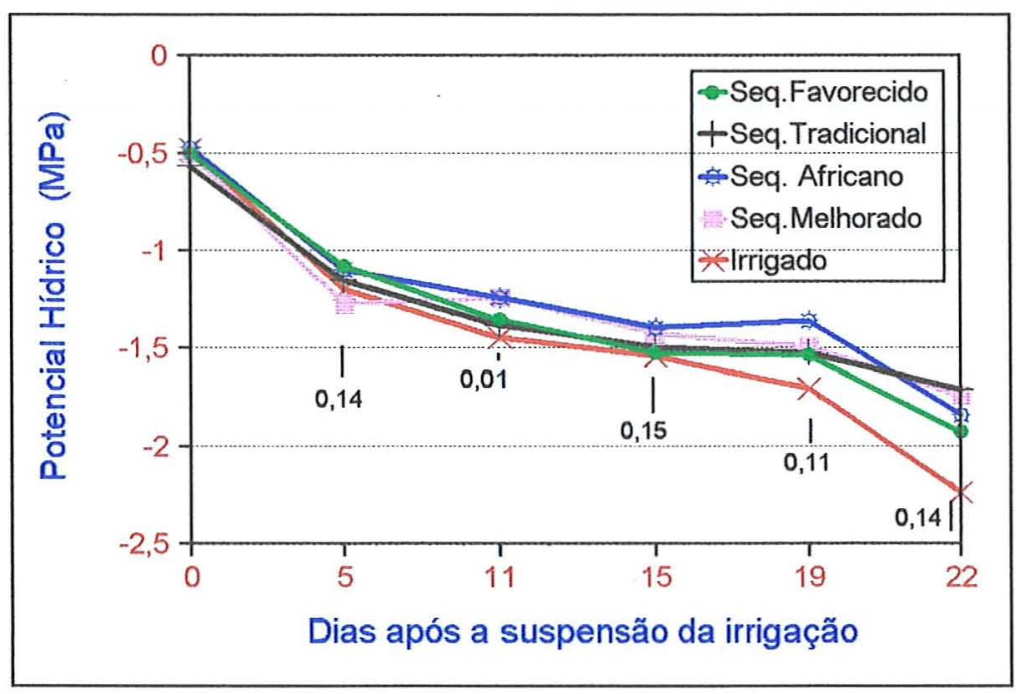

Figura 5. Evolução do potencial hídrico da folha medido ao meio dia no Exp.I, nos cinco grupos em estudo durante a imposição da deficiência hídrica. ${ }^{1}$ Diferença mínima significativa

Ao final do ciclo de deficiência hídrica, quando a umidade do solo decresceu para 18\% (Figura 2.), o potencial da água da folha atingiu $-2.2 \mathrm{MPa}$ no grupo de variedades de arroz irrigado e $-1.9 \mathrm{MPa}$ no de sequeiro favorecido enquanto as variedades de sequeiro tradicional, africano e sequeiro melhorado apresentaram um potencial entre -1.7 MPa e -1,8 MPa (Figura 5). 
Tabela 3. Comparação de médias do potencial da água da folha(MPa) medido ao meio dia, nos cinco grupos em estudo, no Exp.I

\begin{tabular}{lccc}
\hline $\begin{array}{l}\text { Grupos de } \\
\text { Genótipos }\end{array}$ & Dias após & suspensão da irrigação \\
\cline { 2 - 4 } & 15 & 19 & 22 \\
\hline Seq.Favorecido & $-1.52 \mathrm{a}$ & $-1.53 \mathrm{~b}$ & $-1.92 \mathrm{~b}$ \\
Seq.Tradicional & $-1.50 \mathrm{a}$ & $-1.52 \mathrm{~b}$ & $-1.71 \mathrm{c}$ \\
Africano & $-1.40 \mathrm{a}$ & $-1.36 \mathrm{c}$ & $-1.80 \mathrm{bc}$ \\
Irrigado & $-1.54 \mathrm{a}$ & $-1.70 \mathrm{a}$ & $-2.23 \mathrm{a}$ \\
Seq. Melhorado & $-1.42 \mathrm{a}$ & $-1.49 \mathrm{~b}$ & $-1.74 \mathrm{c}$
\end{tabular}

\begin{tabular}{llll}
\hline C.V. $(\%)$ & 14.59 & 10.12 & 10.41
\end{tabular}

Médias seguidas pela mesma letra, no sentido vertical, não diferem entre si (Tukey-5\%)

Assim, o grupo de arroz irrigado demostrou menor capacidade para impedir a formação de um déficit hídrico interno, conforme observado por TURNER et al. (1986a) e VIEIRA et al. (1991). Os grupos de sequeiro melhorado, tradicional e africano demonstraram maior habilidade de evitar esse déficit, corroborando com KRUPP et al. (1972), enquanto o grupo de sequeiro favorecido mostrouse num nível intermediário entre o sequeiro e o irrigado. o comportamento do grupo de sequeiro favorecido é esperado por ter se originado de cruzamento de linhagens de arroz de sequeiro com linhagens de arroz irrigado.

\subsubsection{Características visuais}

O enrolamento foliar é uma característica comum em gramíneas como resposta à deficiência hídrica. 
Como pode-se observar na Figura 6(A), no decorrer do déficit hídrico, todos os grupos portaram-se de maneira semelhante, enrolando suas folhas progressivamente.
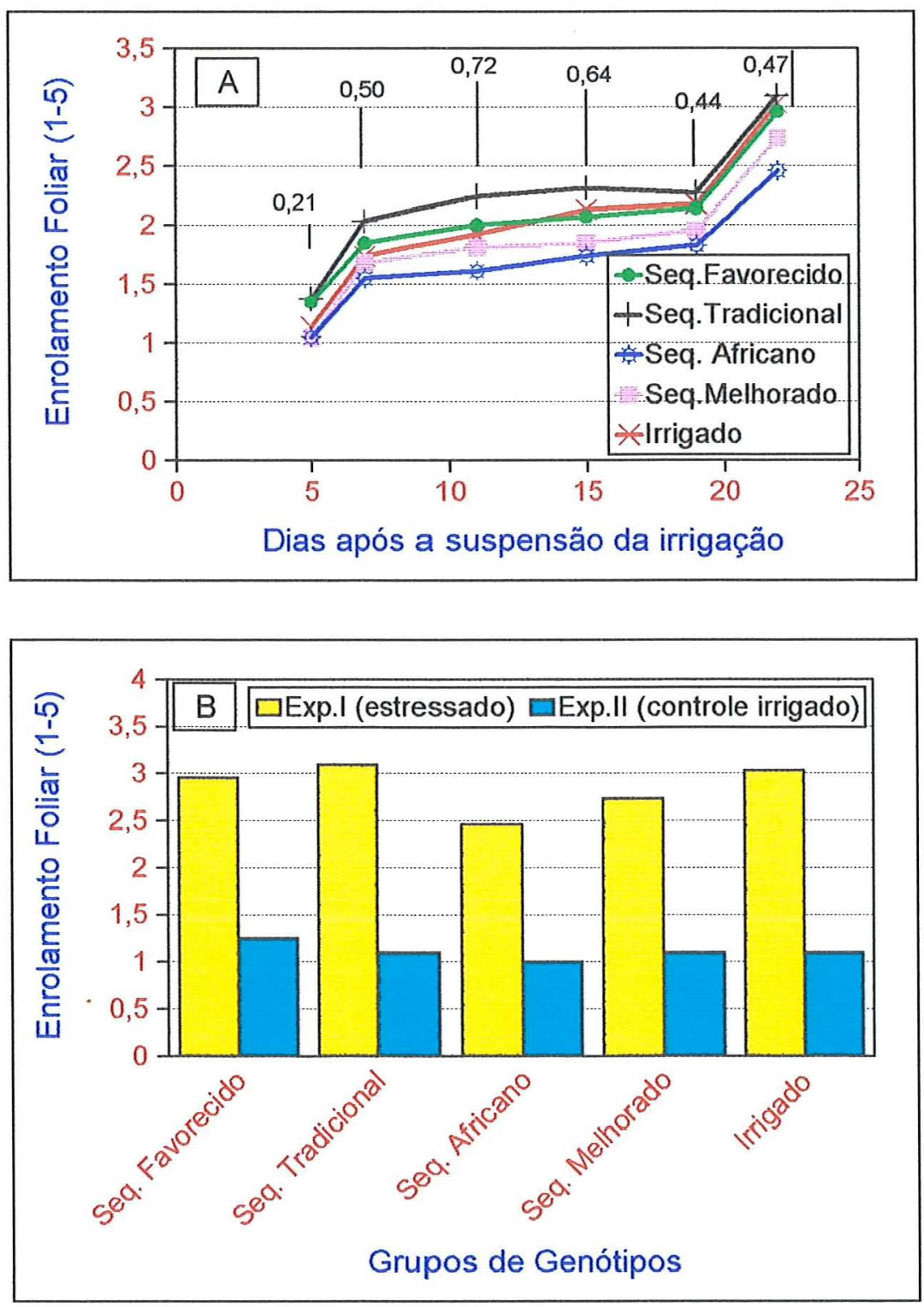

Figura 6. Enrolamento foliar medido pela manhã no Exp.I, durante a suspensão da irrigação (A) e no final do período de estresse no Exp.I e Exp.II (B) . D.M.S. $(\operatorname{Exp} . I)=0.47 ;$ D.M.S. $(\operatorname{Exp} . I I)=0.28$

*Os valores apresentados dentro na Figura A correspondem a diferença mínima significativa 
O enrolamento foliar medido pela manhã demonstra a capacidade de reidratação noturna e com isso, avalia indiretamente o desenvolvimento radicular (O'TOOLE \& MOYA, 1978; O'TOOLE \& CHANG, 1979).

Até os onze dias após a suspensão da irrigação, os grupos de variedades de arroz não diferiram quanto as notas de enrolamento foliar. Após o $15^{\circ}$ dia foi detectada diferença significativa entre grupos (Tukey - 5\%) e aos dezessete dias após a suspensão da irrigação, os grupos de arroz irrigado e de sequeiro favorecido apresentaram maiores níveis de enrolamento (C.V.=14\%) em relação ao sequeiro melhorado e africano (Eigura 6A). No trabalho de O'TOOLE \& CRUZ (1980), a cultivar irrigada também apresentou maiores níveis de enrolamento no decorrer do déficit hídrico.

No caso do grupo das variedades de sequeiro tradicional, que também apresentaram altos níveis de enrolamento no Exp.I (estressado), provavelmente essa reação anômala deve-se à incidência de brusone nas folhas.

É sabido que o déficit hídrico predispõe a planta à doenças (SCHOENEwEISS, 1978). Assim, debilitadas pela seca, e possuindo uma menor resistência à infecção por agentes patogênicos, este grupo apresentou um maior ataque de brusone nas folhas do que os demais, o que pode ter tornado as folhas mais sensiveis ao enrolamento.

No Exp.II (controle irrigado), o grupo de sequeiro tradicional comportou-se quanto ao enrolamento foliar, de forma similar aos outros grupos de sequeiro (Figura 4.6 B). Neste caso, a brusone não ocorreu na mesma intensidade, do que sob condições de deficiência hídrica.

os dados permitiram constatar que os grupos de sequeiro melhorado e africano possuem uma maior 
capacidade de reidratação noturna, apresentando-se com folhas menos enroladas pela manhã.

Estes resultados corroboram com os encontrados por CHANG et al. (1974). Os autores relacionam a reação de enrolamento com o tipo de folha das variedades. Folhas moderadamente longas a longas e ligeiramente decumbentes apresentam plasticidade, ao enrolar as folhas durante o pico de demanda e desenrolá-las quando o estresse hídrico é parcialmente aliviado em manhãs frescas. As variedades de arroz irrigado, com folhas curtas e eretas enrolam suas folhas firmemente em forma de tubo e não desenrolam à noite.

No decorrer da suspensão da irrigação, o grupo de sequeiro melhorado e sequeiro africano apresentaram valores menores de enrolamento foliar. Este atraso em enrolar suas folhas, ao longo da duração do estresse, apesar do déficit hídrico interno da planta estar aumentando, mostra uma melhor resistência à seca nas variedades de sequeiro melhorado e africanas, de acordo com o trabalho de SINGH \& MACKILL (1991).

$\mathrm{Na}$ Figura $7(\mathrm{~A})$, pode-se observar a evolução do secamento das folhas dos grupos de variedades.

A proporção de folhas velhas verdes, e a proporção de queima da ponta das folhas novas durante o período de estresse indicam, também, o nível de tolerância à seca (CHANG et al., 1974).

- grupo de sequeiro tradicional, como comentado anteriormente, teve alta incidencia de brusone mascarando, assim, os resultados de secamento.

Apesar das diferenças observadas na Figura $7 \mathrm{~B}$ os grupos não diferiram significativamente quanto ao parâmetro secamento $(\mathrm{C} \cdot \mathrm{V} \cdot=24,01 \%)$. Possivelmente isto se deva 
às plantas estarem em fase mais avançada do ciclo, quando as folhas já entravam em senescência, mascarando assim o secamento devido ao déficit hídrico.
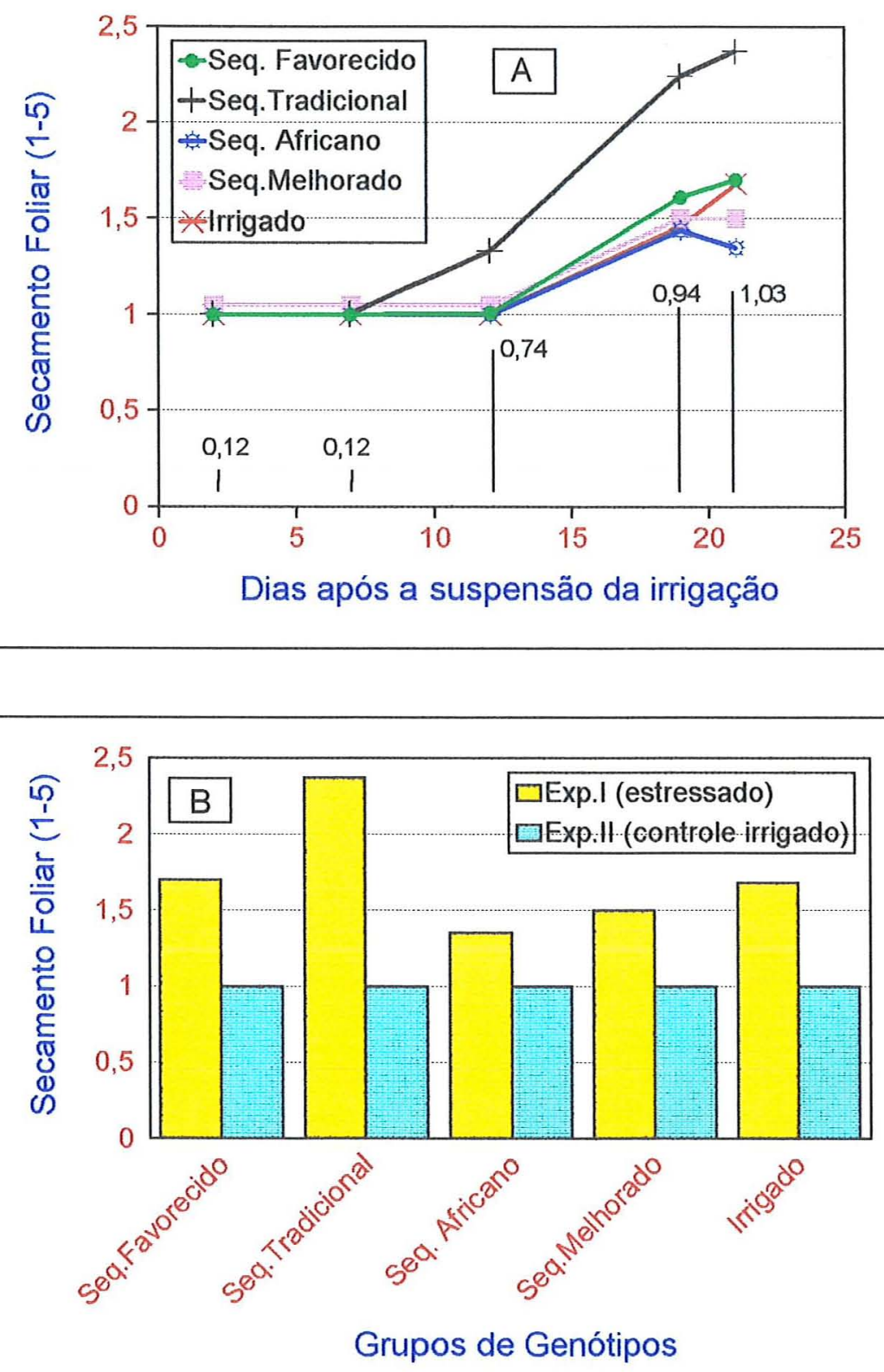

Figura 7. Secamento Foliar no Exp.I durante a suspensão da irrigação (A) e no final da suspensão da irrigação no Exp.I e Exp.II (B); D.M.S. $(\operatorname{Exp} . I)=1.03 ;$ D.M.S. $(\operatorname{Exp} . I I)=0$

* Os valores apresentados dentro da Figura A corespondem a D.M.S. 
Os critérios de avaliação da resistência à seca propostos por LORESTO et al.(1976) e CHANG et al.(1974), levam em consideração o secamento foliar na fase vegetativa e não na fase reprodutiva. Pode-se inferir portanto que a caracteristica "secamento de folhas" avalia melhor os materiais quando a imposição do déficit hídrico é feita na fase vegetativa.

\subsubsection{Exposição da panícula e fertilidade das espiguetas}

Dos processos fisiológicos da planta, o crescimento é o processo mais afetado pela deficiência hídrica (HSIAO, 1973). O alongamento do último entrenó do colmo da planta de arroz, que resulta na exposição da panícula, é seriamente afetado em condições de deficiência hídrica (O'TOOLE \& NAMUCO, 1983; PINHEIRO, 1989).

Os grupos que se comportaram melhor em relação à exposição da panícula foram o sequeiro tradicional e o sequeiro melhorado, que diferiram significativamente dos demais grupos, demonstrando uma menor sensibilidade do processo de crescimento ou maior capacidade de manter o potencial da água em níveis adequados ao crescimento (Figura 8).

Já o grupo de sequeiro africano demonstra uma maior sensibilidade do processo de emissão de panículas, fato este já observado por PINHEIRO ET AL, 1994, para uma cultivar representativa desse grupo.

A menor exposição de panículas do grupo de arroz irrigado no ExpII, deve-se, provavelmente, ao fato de não ser adaptado ao ecossistema sequeiro. Mesmo sob irrigação suplementar o grupo não conseguiu atingir seu potencial de crescimento. 
Na literatura encontra-se que a redução do alongamento do entrenó da panícula $e$, consequentemente, a retenção das espiguetas dentro da bainha da folha, é responsável por parte da esterilidade produzida pela deficiência hídrica neste estágio (O'TOOLE \& NAMUCO, 1983; CRUZ \& O'TOOLE, 1984).

Como pode-se observar na Tabela 4, o grupo de sequeiro melhorado, que apresentou maior exposição de panículas, também apresentou a maior fertilidade de espiguetas.

Tabela 4. Comparação de médias da emissão de panículas (\%) e fertilidade de espiguetas ( $\left.\frac{\circ}{0}\right)$, no Exp.I e Exp.II

Grupos de

Genótipos
Emissão de panículas (\%)
Fertilidade de espiguetas (\%)

Exp.I Exp.II Exp.I Exp.II

\begin{tabular}{lcccc}
\hline Sequeiro Favorecido & $77.26 \mathrm{~b}$ & $90.22 \mathrm{c}$ & $26.50 \mathrm{c}$ & $58.44 \mathrm{c}$ \\
Sequeiro Tradicional & $89.56 \mathrm{a}$ & $97.44 \mathrm{ab}$ & $40.63 \mathrm{~b}$ & $64.48 \mathrm{bc}$ \\
Sequeiro Africano & $81.19 \mathrm{~b}$ & $92.64 \mathrm{bc}$ & $35.19 \mathrm{~b}$ & $67.46 \mathrm{~b}$ \\
Sequeiro Melhorado & $86.28 \mathrm{a}$ & $99.05 \mathrm{a}$ & $48.54 \mathrm{a}$ & $77.00 \mathrm{a}$ \\
Irrigado & $77.91 \mathrm{~b}$ & $82.24 \mathrm{~d}$ & $19.06 \mathrm{~d}$ & $50.32 \mathrm{~d}$
\end{tabular}

$\begin{array}{lllll}\text { C.V. }(\%) & 7.11 & 5.61 & 22.65 & 14.70\end{array}$

Médias seguidas pela mesma letra, no sentido vertical, não diferem entre si (Tukey-5\%)

Em alguns casos, a retenção da panícula dentro da bainha pode prover uma reação de escape à deficiência hídrica. Mas esta retenção só é válida em curtos períodos de estresse, onde após a suspensão do déficit hídrico, a panícula retoma seu crescimento e produz com menores perdas. No estudo de PINHEIRO (1989), as panículas que permaneceram na bainha durante o período de imposição da deficiência hídrica apresentaram um maior potencial da água do que aquelas que floresceram no mesmo período. 
Cabe aqui recordar que, os dados de exposição da panícula no presente estudo, foram tomados já na maturidade após um longo período de estresse, ou seja, onde a parte da panícula retida dentro da bainha já não poderia mais sair e retomar o processo de formação de grãos.
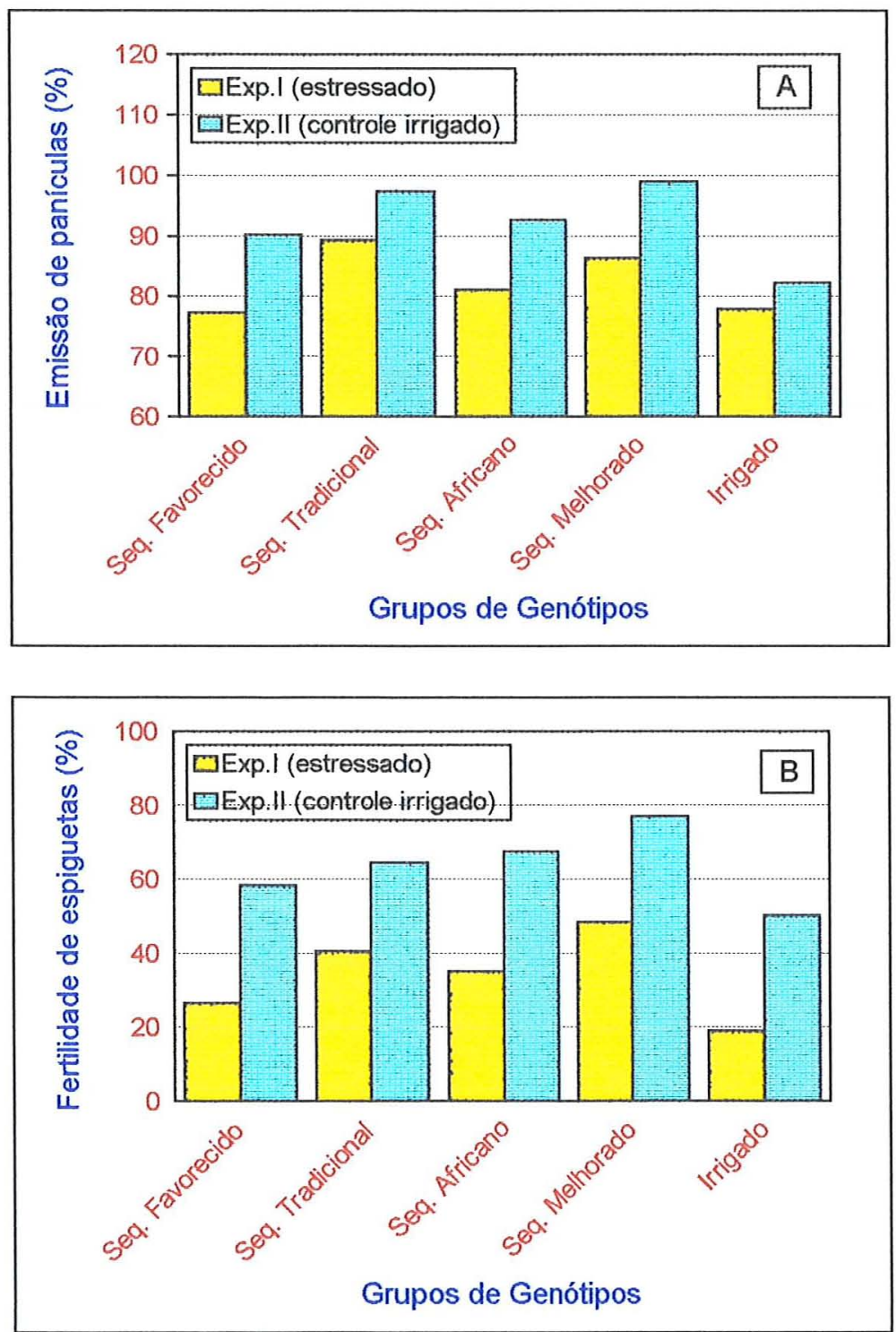

Figura 8. Percentagem de emissão de panículas D.M.S. $(\operatorname{Exp} . I)=4.61 ;$ D.M.S. $(\operatorname{Exp} . I I)=6.22$ (A) e fertilidade de espiguetas D.M.S. $(\operatorname{Exp} . I)=6.18 ;$ D.M.S. $(\operatorname{Exp} . I I)=6.75(B)$ no Exp.I e Exp.II. 
Apesar da adequada taxa de emissão de panículas do grupo de sequeiro tradicional, este apresentou uma menor fertilidade de espiguetas que o grupo de sequeiro melhorado e africanos. Como comentado anteriormente, o grupo de sequeiro tradicional, apesar do controle químico utilizado, apresentou uma alta infecção por brusone, sendo esta a causa da sua menor fertilidade em relação aos demais grupos de sequeiro.

\subsubsection{Altura de planta e biomassa}

A redução da altura da planta também pode ser usada como um indicador de resistência à seca (DeDATTA et al., 1975). De acordo com a Eigura 9, o grupo de arroz irrigado não apresentou uma maior redução na altura das plantas que os grupos de sequeiro em resposta à seca, contrastando com o observado por CHANG et al. (1972). Este é mais um indicativo de que esse grupo não apresentou pleno desenvolvimento no Exp.II., corroborado pela baixa estatura média desenvolvida pelas plantas (Tabela 5). 

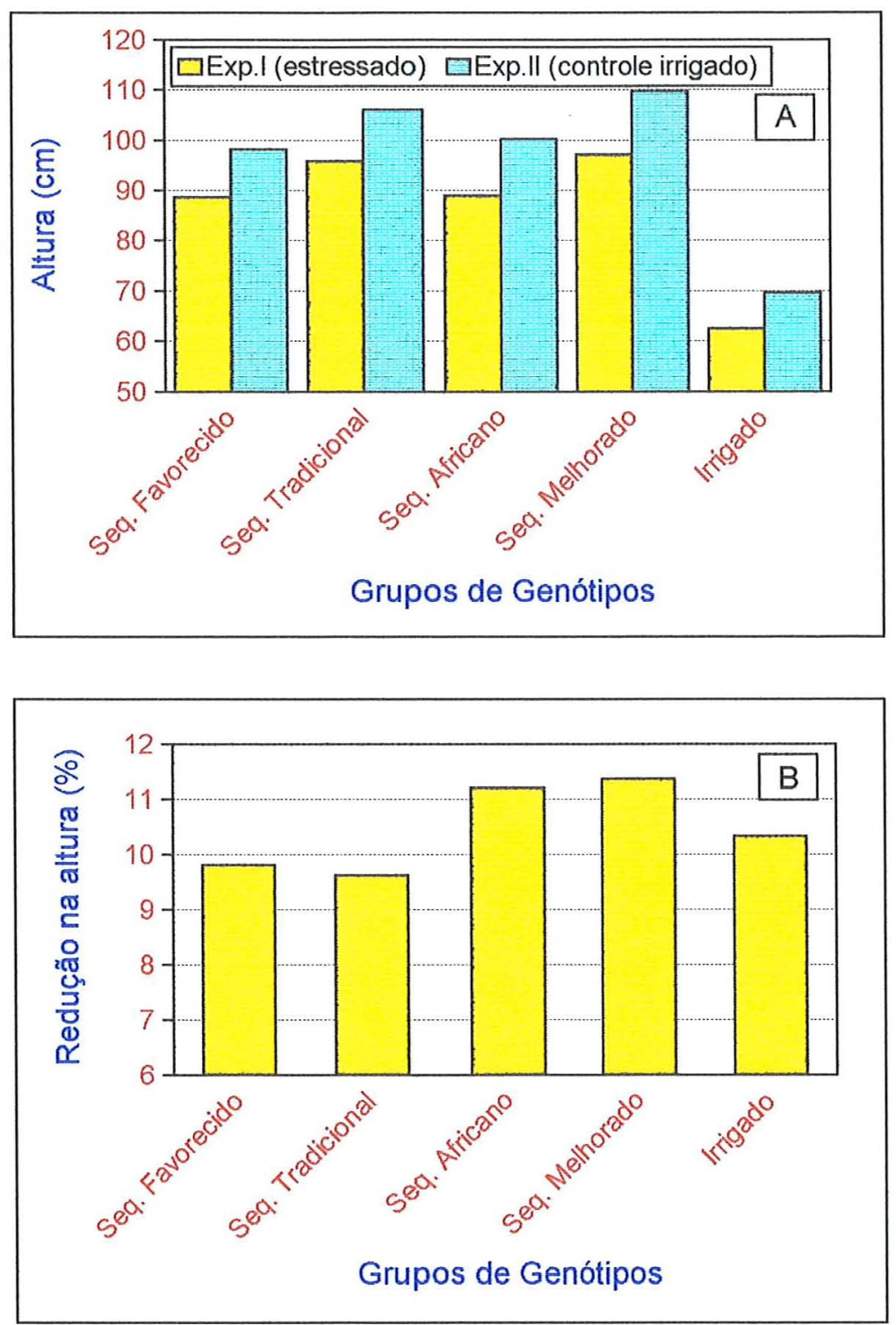

Figura 9. Altura média de plantas dos grupos de genótipos no Exp.I e Exp.II - D.M.S. (Exp.I) =4.81; D.M.S. $(\operatorname{Exp} . I I)=13.83(\mathrm{~A})$ e redução na altura no experimento estressado em relação ao controle irrigado (B)

Tanto no Experimento I como no Experimento II, houve diferenças significativas (Tukey-5\%) na altura, como podemos observar na Tabela 5 . 
Tabela 5. Comparação de médias da altura de plantas (cm) na maturidade no Exp.I e Exp.II e a percentagem de redução do Exp.I em relação ao Exp.II

\begin{tabular}{lccc}
\hline $\begin{array}{l}\text { Grupos de } \\
\text { Genótipos }\end{array}$ & $\begin{array}{c}\text { Exp. I } \\
\text { (estressado) }\end{array}$ & $\begin{array}{c}\text { Exp.II } \\
\text { (controle irrigado) }\end{array}$ & $\begin{array}{c}\text { Redução } \\
\text { (\%) }\end{array}$ \\
\hline Sequeiro Favorecido & $88.62 \mathrm{~b}$ & $98.27 \mathrm{a}$ & 9.91 \\
Sequeiro Tradicional & $95.85 \mathrm{a}$ & $106.07 \mathrm{a}$ & 9.63 \\
Sequeiro Africano & $89.01 \mathrm{~b}$ & $100.26 \mathrm{a}$ & 11.22 \\
Sequeiro Melhorado & $97.19 \mathrm{a}$ & $109.68 \mathrm{a}$ & 10.23 \\
Irrigado & $62.54 \mathrm{c}$ & $69.75 \mathrm{~b}$ & 11.38 \\
\hline \multicolumn{1}{c}{ C.V. $(\%)$} & 5.53 & 6.37 & \\
\hline
\end{tabular}

Médias seguidas pela mesma letra, no sentido vertical, não diferem entre si (Tukey-5\%)

Não houve diferença significativa no peso médio da biomassa da parte aérea coletada em pleno florescimento (Figura 10). Esses resultados também foram encontrados por ALLURI et al., (1982) com variedades de origem diferente conduzidas em condições de sequeiro. 0 mesmo ocorreu no trabalho de TURNER et al. (1986a).

A biomassa foi coletada na metade do período de déficit hídrico, aproximadamente no $12^{\circ}$ dia, 0 mesmo ocorrendo no trabalho dos autores citados com relação ao período de deficiência hídrica. Já, no trabalho de JosHI (1968), onde este período foi maior, as variedades mais resistentes à seca apresentaram uma maior biomassa da parte aérea ao final do estresse. 


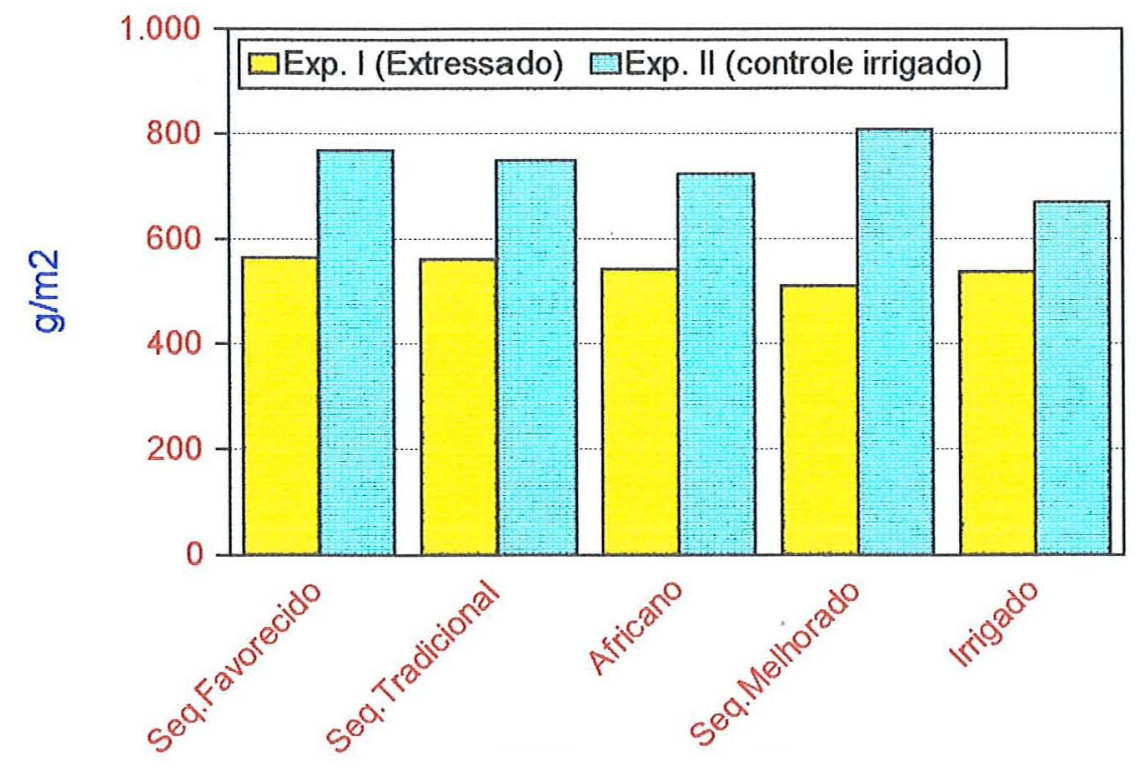

Grupos de genótipos

Figura 10. Biomassa na fase de florescimento de cinco grupos de genótipos no Exp.I e Exp.II

4.2.6. Rendimento e avaliação global da resistência à seca

Houve

diferenças

significativas estatisticamente (Tukey - 5\%) para o rendimento de grãos entre os grupos de genótipos em estudo (Tabela 6).

Tabela 6. Comparação de médias do rendimento de grãos (Kg/ha) dos grupos de genótipos no Exp.I e Exp.II

\begin{tabular}{lccc}
\hline $\begin{array}{l}\text { Grupos de } \\
\text { Genótipos }\end{array}$ & $\begin{array}{c}\text { Exp.I } \\
\text { (estressado) }\end{array}$ & $\begin{array}{c}\text { Exp. II } \\
\text { (controle irrigado) }\end{array}$ & $\begin{array}{c}\text { Perdas } \\
\left(\frac{\circ}{8}\right)\end{array}$ \\
\hline Sequeiro Favorecido & $521.5 \mathrm{c}$ & $2356.5 \mathrm{abc}$ & 77.87 \\
Sequeiro Tradicional & $500.7 \mathrm{c}$ & $1937.4 \mathrm{c}$ & 74.16 \\
Africano & $766.6 \mathrm{~b}$ & $2544.1 \mathrm{ab}$ & 68.86 \\
Irrigado & $470.4 \mathrm{c}$ & $2066.4 \mathrm{bc}$ & 77.23 \\
Sequeiro Melhorado & $986.1 \mathrm{a}$ & $2770.8 \mathrm{a}$ & 64.41 \\
\hline
\end{tabular}

C.V. (\%)

28.43

22.70

Médias seguidas pela mesma letra, no sentido vertical, não diferem entre si (Tukey-5\%) 

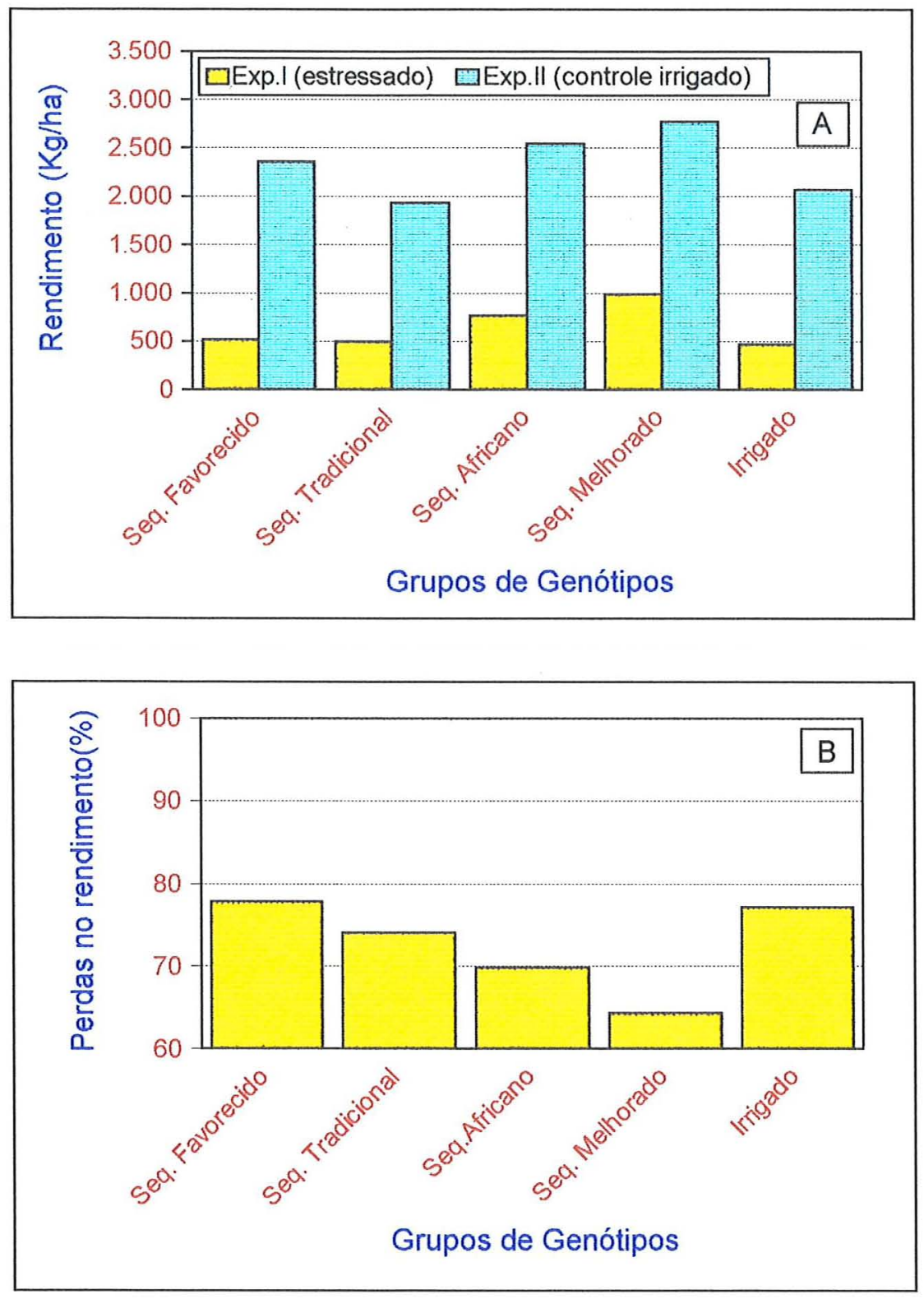

Figura 11. Rendimento médio de grãos dos grupos de genótipos no Exp.I (D.M.S.=209.54) e Exp.II (D.M.S.=567.91) (A) e percentagem de perda no rendimento do experimento estressado em relação ao controle irrigado (B) .

A Figura $11 \mathrm{~B}$ indica que 0 grupo dos genótipos de sequeiro melhorado e africano são os que melhor se adaptaram às condições de deficiência hídrica, pois foram 
os grupos que apresentaram as menores perdas no rendimento em relação ao controle irrigado.

o grupo do sequeiro tradicional, que se esperava também apresentasse uma menor quebra de rendimento, foi prejudicado pela alta incidência de brusone sob condições de deficiência hídrica em relação ao controle irrigado. Isso levou a uma menor fertilidade de espiguetas e, consequentemente, um menor rendimento de grãos.

$\mathrm{Na}$ Figura $11 \mathrm{~B}$ pode-se observar que as maiores perdas de rendimento em relação ao controle irrigado, ocorreram nos grupos de sequeiro favorecido e irrigado, mostrando sua maior sensibilidade à seca.

As perdas no rendimento de uma condição normal para uma condição de deficiência hídrica são úteis na avaliação da resistência à seca (CHANG et al., 1974).

Eoi feita uma análise global de resistência à seca, aplicando-se a escala de avaliação de LORESTO et al. (1976) sobre os dados coletados no estudo. Nos casos de dúvida na atribuição da nota, considerou-se como parâmetro mais relevante a fertilidade de espiguetas. Os resultados são apresentados na Tabela 7 . e Figura 12. 
Tabela 7. Nota de resistência à seca obtida a partir de escala de LORESTO et al. (1976) em cinco grupos de genótipos.

Grupos de

variedades
Resistência

à seca ${ }^{1}$
Sequeiro Favorecido

Sequeiro Tradicional

Africano

Sequeiro Melhorado

Irrigado
$5.9 \mathrm{ab}^{2}$

5.1 bc

$5.0 \mathrm{c}$

$4.0 \mathrm{~d}$

$6.1 \mathrm{a}$

${ }^{1}$ Os menores valores são os desejados

${ }^{2}$ Significativo a $1 \%$ de probabilidade (Tukey)

C.V. $=19,6 \%$

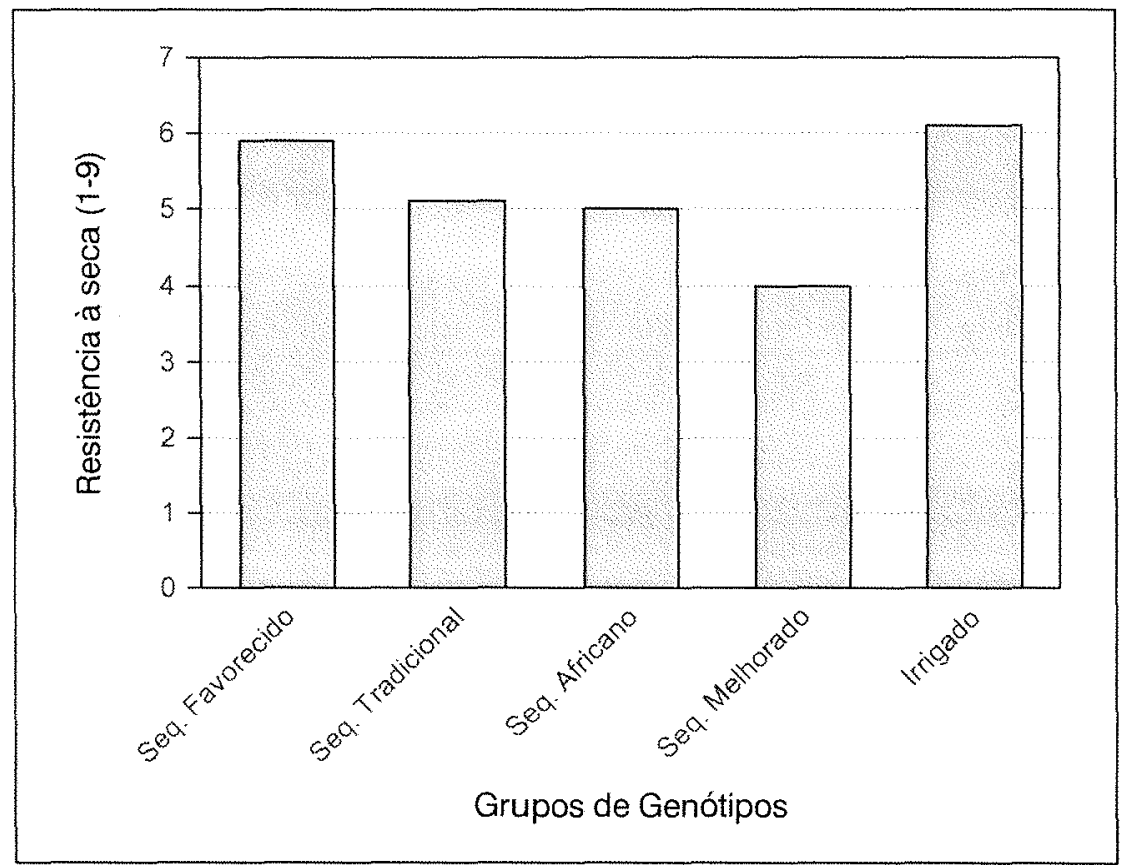

Figura 12. Notas de resistência à seca obtidas pelos cinco grupos de genótipos utilizando a escala de Loresto et al (1976) 
Apesar das significativas diferenças entre grupos no que se refere a rendimento e demais parâmetros em consideração, a avaliação da resistência à seca indicou uma diferença entre os extremos de apenas 2,1 pontos (escala de 1-9) no desempenho dos grupos. Dessa forma o grupo de sequeiro melhorado, que oteve nota 4,0 classifica-se como moderadamente resistente, enquanto o grupo irrigado, com nota 6,1 , se classifica como moderadamente suscetivel.

A Figura 13 indica a existência de variabilidade genética para a resistência à seca tanto entre quanto dentro de grupos. Observa-se que os grupos de arroz irrigado e de sequeiro favorecido classificam-se como moderadamente suscetíveis a suscetíveis para a maioria dos genótipos testados. Contudo, mesmo nesses grupos há genótipos moderadamente resistentes.

Os grupos de sequeiro tradicional, africano e melhorado apresentaram-se como moderadamente resistentes a moderadamente suscetíveis. Destaca-se o bom desempenho médio do sequeiro melhorado, em que a maioria dos genótipos classificou-se como moderadamente resistente. 


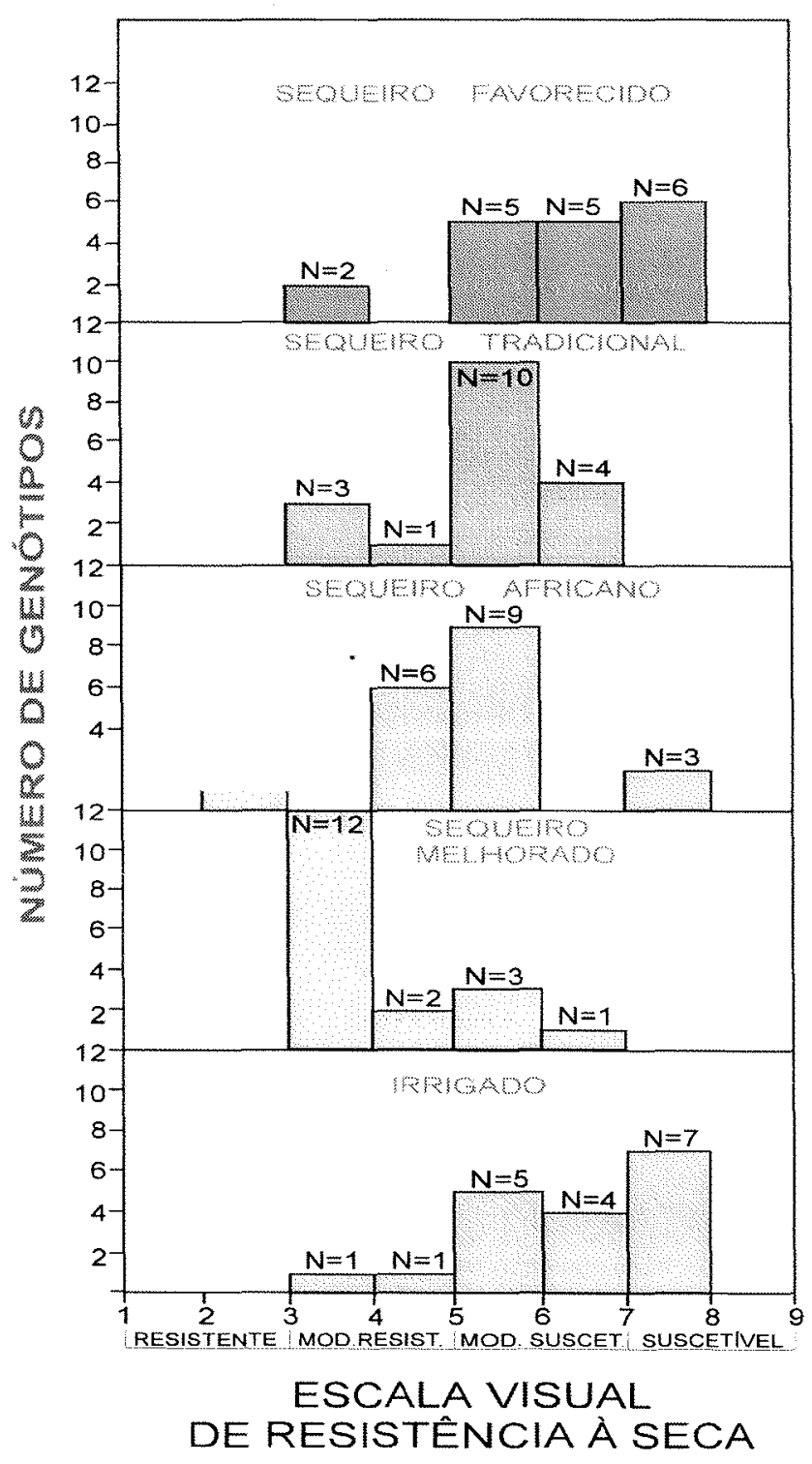

Figura 13. Distribuição da nota de avaliação de resistência à seca em cinco grupos de variedades

Assim, apesar da ausência de seleção direta para resistência à seca nos programas de melhoramento, as variedades de sequeiro melhorado conservaram as características de resistência à seca das variedades que thes deram origem, em sua maioria do grupo japonica (variedades tradicionais e africanas). 
Em contraste com esse sucesso, destaca-se a menor resistência à seca do grupo de sequeiro favorecido, em cuja composição contribuíram genitores do grupo indica e japonica.

\subsection{Associações entre $\circ$ rendimento e os vários parâmetros de resistência à seca}

De acordo com a Tabela 8, a maioria dos parâmetros de resistência à seca relacionaram-se com a produtividade nos dois experimentos. Isto se deve à significativa relação entre os rendimentos obtidos nos dois ambientes. Tanto no Exp.I como no Exp.II, a fertilidade de espiguetas destaca-se como um parâmetro estreitamente associado ao rendimento. Essa estreita associação em condições de deficiência hídrica tem sido reportado na literatura (PINHEIRO et al., 1985, 1990).

Ainda na Tabela 8 , observa-se que no experimento extressado a nota de resistência à seca associou-se de forma ainda mais estreita ao rendimento do que a fertilidade das espiguetas. Isto indica ser a escala de avaliação visual um critério bastante preciso de comparação entre genótipos.

Essa nota também se associou ao rendimento do controle irrigado, apesar do pequeno valor da correlação. Tal associação, conjugada àquela observada entre os rendimentos nos dois ambientes, dá indícios de que o bom desempenho sob deficiência hídrica depende também de um bom 
potencial de rendimento ( ARRAUDEAU, 1989; O'TOOLE \& MOYA, 1981).

Tabela 8. Associações desenvolvidas entre produtividade, a nota de resistência à seca e demais variáveis, medidas no experimento que desenvolveu deficiência hídrica (Exp.I) e no controle irrigado (Exp. II) - N=90

\begin{tabular}{|c|c|c|c|c|c|c|c|}
\hline Variáveis & Exp. & REND $^{\prime}$ & NOTA & PEP & FLO50 & FERT & SEC \\
\hline REND & IXII & $0.530 * *$ & & & & & \\
\hline \multirow[t]{2}{*}{ NOTA } & $I$ & $-0.878^{* *}$ & & & & & \\
\hline & II & $0.330^{* *}$ & & & & & \\
\hline \multirow[t]{2}{*}{ PEP } & $\mathrm{I}$ & $0.272 * *$ & $-0.447 * *$ & & & & \\
\hline & II & $0.373^{* *}$ & & & & & \\
\hline \multirow[t]{2}{*}{ EL050 } & $\mathrm{I}$ & $-0.329 * *$ & $0.144^{*}$ & 0.109 n.s. & & & \\
\hline & II & $-0.308^{* *}$ & & $-0.145^{*}$ & & & \\
\hline \multirow[t]{2}{*}{ FERT } & $\mathrm{I}$ & $0.600^{* *}$ & $-0.707 * *$ & $0.616^{* *}$ & -0.007 n.s. & & \\
\hline & II & $0.597 * *$ & & $0.475^{* *}$ & -0.119 n.s. & & \\
\hline \multirow[t]{2}{*}{ ENR } & $\mathrm{I}$ & $-0.254 * *$ & $0,205^{* *}$ & 0.035 n.s. & -0.061 n.s. & $-0.133^{*}$ & $0.401^{* *}$ \\
\hline & II & -0.092 n.s. & & 0.009 n.s. & -0.002 n.s. & -0.032 n.s. & -- \\
\hline SEC & $I$ & $-0.282 * *$ & 0.177 n.s. & $0.123^{*}$ & $0.234^{* *}$ & -0.019 n.s. & - \\
\hline
\end{tabular}

${ }^{1}$ REND $=$ Rendimento de grãos

NOTA $=$ Nota de resistência à seca

PEP = Emissão de panículas

FLO50 = Número de dias até $50 \%$ do florescimento

FERT $=$ Fertilidade de espiguetas

SEC = Secamento de folhas no final da imposição da deficiência hídrica

ENR = Enrolamento de folhas no final da imposição da deficiência hídrica

Contudo os parâmetros de avaliação da resistência à seca foram mais importantes no desempenho dos grupos do que o rendimento do controle irrigado. Enquanto a associação entre os rendimentos foi de 0.53, aquela entre a nota de resistência à seca e o rendimento no Exp. I foi de 0.88 (Tabela 8).

A inspeção das correlações entre a nota de resistência à seca e as variáveis que serviram à sua 
determinação (Tabela 8) salienta novamente a grande relevância da fertilidade de espiguetas como parâmetro visual de avaliação. O enrolamento, apesar de mais facilmente avaliado, não teve um papel tão relevante no resultado final da avaliação.

Assim, na impossibilidade de aplicar a escala de resistência à seca de LORESTO \& CHANG (1981) sobre um grande número de entradas, a fertilidade das espiguetas destaca-se como um parâmetro relevante e de fácil observação através de escala visual. 


\section{CONCLUSÕES}

1.Os grupos de variedades diferiram na maior parte dos parâmetros avaliados em presença de deficiência hídrica na fase reprodutiva.

2.Os grupos de arroz de sequeiro melhorado e sequeiro africano apresentaram um melhor desempenho em relação aos grupos de sequeiro favorecido e irrigado denotando maior capacidade de evasão.

3.0 grupo de arroz de sequeiro melhorado teve bom desempenho tanto em resistência à seca quanto em rendimento nos dois experimentos, demonstrando o sucesso do melhoramento mesmo na ausência de seleção para resistência à seca.

4.0 pior desempenho dos materiais de sequeiro favorecido, frente aos demais grupos de sequeiro ilustra o risco de cruzar japonica com indica de forma aleatória. 
5.A existência de variabilidade para a resistência à seca dentro dos grupos pode ser utilizada em benefício do melhoramento de plantas. Contudo ao cruzar indica com japonica faz-se recomendável a avaliação prévia da resistência à seca dos genitores. 


\section{REFERÊNCIAS BIBLIOGRÁFICAS}

AHMADI, N. Variabilité genétique et hérédité de mécanismes de tolérance à la sécheresse chez le riz oriza sativa L.:1. dévelopment du systéme racinaire. Agronomie Tropicale, v.38, n.2, p.110-17. 1983.

ALLURI, K. \& VERGARA, B.S. Leaf angle and drought resistance in upland rice. Sabrao Journal, v.8, n.1, p.41-6. 1976.

ALLURI. K.; YAMAGUCHI, J.; ADJA, J.C. \& KAUNG-ZAN. Breeding and selection for plant type em dryland rice. In: INTERNATIONAL RICE RESEARCH INSTITUTE. Drought resistance in crop: with enphasis on rice. Los Baños, Philippines, 1982. p.293-300.

APARICIO-TEJO, P.M. \& BOYER, J.S. Significance of accelerated leaf senescence at low water potentials for water loss and grain yield in maize. Crop Science, V.23, P.1198-202, Nov/Dez. 1983. 
ARMENTA-SOTO, J.; CHANG, T.T.; LORESTO,G.C.; O'TOOLE, J.C. Genetic analysis of root characters in rice. Sabrao Journal, v.15, p.103-16. 1983.

ARRAUDEAU, M.A. \& VERGARA, B.S. A farmer's primer on growing upland rice. Manila: IRRI, 1988. $284 \mathrm{p}$.

ARRAUDEAU, M.A. Breeding strategies for drought resistance. In: BAKER, E.W.G., ed. Drought resistance in cereals. Wallingford: CAB International, 1989. p.107-16.

BANNISTER, R. Water relations of plants. In: Introduction physiological plant ecology. Oxford: Blackwel1, 1976. p.131-67.

BLUM, A. Evidence for genetic variability in drought resistance and its implications in plant breeding. In: INTERNATIONAL RICE RESEARCH INSTITUTE. Drought resistance in crop: with enphasis on rice. Philippines: 1982. p. $53-68$.

BOIS, J.F. \& COUCHAT, P.H. Comparasion of the effects of water stress on the root systems of two variedades of upland rice (Oryza sativa L.). Annals of Botany, v.52, p. 479-87. 1983 .

BOIS, J.E.; COUCHAT, P.H. \& MOUTONNET, P. Estude da la response à um stress hydrique de quelques varietés de riz pluvial et de riz irrigué. I. Incidence sur la transpiration. Plant and soil, v.80, p.227-36. 1984. 
BOYER, J. \& MCPHERSON, H.G. Physiology of water deficits in cereal grains. In: Symposium on Climate and Rice, Philippines, 1976. Climate and Rice. Philippines: IRRI, 1976. p. $321-43$.

CHANG, T.T.; ARMENTE-SOTO, J.L.; MAO, C.X.; PEIRIS, R. \& LORESTO, G.C. Genetic studies on the components of drought resistence in rice. In: INTERNATIONAL RICE GENETICS SYMPOSIUM, Los Baños, 1985. RICE GENETICS, Los Baños: IRRI, 1986. p.387-98.

CHANG, T.T. \& LORESTO, G.C. Germplasm resources and breeding for drought resistance. In: JAKARIA CONFERENCE, Philippines, 1985. Progress in upland rice research. Philippines: IRRI, 1986. p.199-212.

CHANG, T.T.; LORESTO, G.C. \& TAGUMPAY, O. Agronomic characteristics of upland and lowland rice varieties. In: IRRI, ed. Rice Breeding. Philippines: IRRI, 1972. P. 645-61.

CHANG, T.T.; LORESTO, G.C. \& TAGUMPAY, O. Screening rice germplasm for drought resistance. Sabrao Journal, v.6, n.1, p.9-16. 1974.

CHANG, T.T.; LORESTO, G.C.; O'TOOLE, J.C. \& ARMENTA-SOTO, J.I. Strategy and methodology of breeding rice for drought prone areas. In: International Rice Research Institute. Drought resistance in crop: with enphasis on rice. Philippines: IRRI, 1982. p.217-44. 
CHAUDHARY. T.N. \& GHILDYAL, B.B. Water deficiency in the leaves of rice plants as influenced by soil temperature regimes. Indian Journal Agricutural Science, v.40. n.1, p.24-8. 1970 .

CENTRO INTERNACIONAL DE AGRICULTURA TROPICAL (CIAT). Sistema de Evaluación Estándar para arroz. $2^{\circ}$ ed. MANUEL ROSERO (traductor y adaptador). Cali, Colombia, 1983. 61p.

CRUZ, R.T. \& O'TOOLE, J.C. Dryland rice response to an irrigation gradient at flowering stage. Agronomy Journal, v.76, p.178-83, Mar/Abr. 1984.

DAS, G.R. \& AHMED,T. Effect on rice yield of root damage to seedlings. International rice research Newsletter, v.14, n.6, p.5-6, Dez. 1989.

DeDATTA, S.K. \& SESHU, D.U. Evaluation rices for drought tolerance using field screening and multilocation testing. In: INTERNATIONAL RICE RESEARCH INSTITUTE. Drought resistance in crop: with enphasis on rice. Philippines: 1982. p.245-63.

DeDATTA, S.K.; CHANG, T.T. \& YOSHIDA, S. Drought tolerance in upland rice. In: INTERNATIONAL RICE RESEARCH INSTITUTE. Major research in upland rice. Philippines: 1975. p.101-16.

DERERA, N.F.; MARSHALL, D.R.; BALAAM, L.N. Genetic variability in root development in relation to drought tolerance in spring wheats. Experimental Agriculture, v. 5, p.327-37. 1969. 
DINGKUHN, M.; CRUZ, R.T.; O'TOOLE, J.C. \& DÖREFLING, K. Net photosynthesis, water use efficiency, leaf water potential and leaf rolling as affected by water deficit in tropical upland rice. Australian Journal Agriculture Research, v.40, p.1171-91. 1989.

EKANAYAKE, I.J.; O'TOOLE, J.C.; GARRITY, D.P.; MASAJO, T.M. Inheritance of root characters an their relations to drought resistance in rice. Crop Science, v.25, p.92733. 1985.

EMPRESA BRASILEIRA DE PESQUISA AgROPECUÁRIA BRASILEIRA. CENTRO NACIONAL DE PESQUISA DE ARROZ E FEIJÃO. A pesquisa de arroz no Brasil nos anos 80: avaliação crítica dos principais resultados. EMBRAPA/CNPAF. Documentos, 40. Goiânia, GO. 1994. 406p.

EMPRESA BRASILEIRA DE PESQUiSA AGROPECUÁRIA BRASILEIRA. CENTRO NACIONAL DE PESQUiSA DE ARROZ E EEIJÃO. Agrometeorologia e Fisiologia. Relatório Científico. p. 93-113. 1984 .

EMPRESA BRASILEIRA DE PESQUISA AGROPECUÁRIA BRASILEIRA. Departamento Técnico Científico. Brasilia, DF. Programa Nacional de Pesquisa de Arroz. Brasília: EMBRAPA - DID. 1981. 69p.

GARRITY, D.P. \& O'TOOLE, J.C. Screening rice for drought resistance at the reproductive phase. Field Crops Research, v.39, n.2,3, p. 99-100, Dec. 1994. 
GLASZMANN, J.C. A varietal classification of Asian cultivated rice (Oryza sativa L.) based on isozyme polymorphism. In: INTERNATIONAL RICE GENETICS SYMPOSIUM, Philippines, 1985. Rice Genetics. Philippines: IRRI, 1986. p. 83-90.

GOMATHINAYAGAM, P.; INGRAM, K.T. \& MAGULING, M.A. Pot screening for drought tolerance in rice. International Rice Research Newsletter, v.13, n.6, p.19. Dec. 1968.

GOMEZ, K.A. \& GOMEZ, A.A. Statistical procedures for agricultural research. New York: Wiley Interscience, 1984. Cap.2, p.7-83: Single-factor experiments/2.5. Group balanced block design, p.75-83.

GRIST, D.H. Characteristics of the plant. In:

Rice. 6.ed. New York: Longman, 1986. cap.5, p.69-98.

HSIAO, T.C. Plant response to water stress. Annual Review Plant Physiology, v.24, p.519-70. 1973.

INGRAM, K.T.; REAL, M.A.; MAGULING, M.A.; OBIEN, M.A. \& LORESTO, G.C. Comparison of selection indices to screen lowland rice for drought resistance. Euphytica, v.48, p.253-60. 1990.

INSTITUT DE RECHERCHES AGRONOMIQUES TROPICALES ET DES CULTIRES VIVRIĖRES (IRAT). Département du Centre de Coopération Internationale en Recherche Agronomique pour le Développment (CIRAD). Montpellier, 1989. sem paginação. 
INTERNATIONAL RICE RESEARCH INSTITUTE. Program Report for 1989. Philippines, 1989. p.110-1.

JENNINGS, P.R.; COFEMAN, W.R. \& KAUEFMAN, H.E. MEJORAMIENTO DE ARROZ. Cali: CIAT, 1981. cap.9, p.225-32: Adaptabilidad a condiciones de secano.

JONES, C.A. Effect of drought stress on percentage filled grains in upland rice. Tropical Agriculture, v.58, n.3, p.201-3, Jul. 1981.

JONES, H.G. Visual estimation of plant water status in cereals. Journal Agriculture Science. v.92, p.83-9. 1979.

JONES, M.M.; TURNER, N.C.; OSMOND, C.B. Mechanisms of drought resistance. In: PALEG, L.G. \& ASPINALL, D., ed. The physiological and biochemistry of drought resistance in plants. New York: Academis Press, 1981. p.15-53.

JORDAN, W.R. \& MILLER, E.R. Genetic variability in sorghum root systems: implications for drought tolerance. In: TURNER, N.C. \& KRAMER, P.J., ed. Adaptation of plants to water and high temperature stress. New York: John Willey, 1980. p.383-99.

JOSHI, S.N. Study on some morphological attributes for drought resistance in drilled paddy genotypes. Indian Journal Agriculture Science, v.39, n.6, p.500-5. 1968.

KLUTHCOUSKI, J. \& YOKOYAMA, L.P. O arroz nos sistemas de cultivo do cerrado. In: Conferência Internacional de 
Arroz para a América Latina e para o Caribe, 9., 1994. Goiânia. Conferências. Goiânia: EMBRAPA - CNPAF/CIAT, 1994. 18p.

KRAMER, P.J. Plant and soil water realationships: A modern synthesis. New York: McGraw-Hill, 1980. 482p.

KRUPP, H.K.; ABILAY, W.P. \& ALVAREZ, E.I. Some water stress effects on rice. In: INTERNATIONAL RICE RESEARCH INSTITUTE. Rice Breeding. Los Baños, 1972. p.663-74.

LEVITT, J. Responses of plants to environmental stress. London: Academic Press, 1972. 697p. LEVITT, J. Stress terminology. In: TURNER, N.C. \& KRAMER, P.J. eds. Adaptation of plants to water and high temperature stress. New York: John Willey, 1980. p.4379 .

LORESTO, G.C. \& CHANG, T.T. Decimal scoring systems for drought reaction and recovery ability in rice screening nurseries. International Rice Research Newsletter, v.6, n.2, p.9-10. 1981.

LORESTO, G.C.; CHANG, T.T. \& TAGUMPAY, O. Field evaluation and breeding for drought resistance. Philippine Journal of Crop Science, V.1, n.1, p.36-9. 1976.

MANBANI, B. \& LAL, R. Response of upland rice varieties to drought stress. I. Relation between root system development and leaf water potential. Plant and soil, v.73, p.59-72. 1983a. 
MANBANI, B. \& LAL, R. Response of upland rice varieties to drought stress. II. Screening rice varieties by means of variable moisture regimes along a toposequence. Plant and soil, v.73, p.73-94. 1983b.

MANBANI, B. \& LAL, R. Response of upland rice varieties to drought stress. III. Estimating root system configuration from soil moisture data. Plant and soil, v.73, p.95-104. 1983c.

MCWILLIAN, J.R. The dimensions of drought. In: BAKER, F.W.G. ed. Drought resistance in cereals. Wallingford: CAB International, 1989. p.1-12.

MORAIS, O.P.; SANT'ANA, E.P.; CHATEL, M.; PRABHU, A.S.; CASTRO. E.M. Melhoramento genético voltado para a cultura do arroz de sequeiro. In: INSTITUTO DA POTASSA E FOSFATO. Cultura do arroz de sequeiro; fatores afetando a produtividade. Piracicaba: IPF, 1983. p. 145-72.

O'TOOLE, J.C.. Adaptation of rice to drought-phone environments. In: Drought resistance in crops with emphasis on rice. Philippines: IRRI, 1982. p.195-213.

O'TOOLE, J.C. \& CHANG, T.T. Drought and rice improvement perspective. Philippines: IRRI, 27p. 1978. (paper).

O'TOOLE, J.C. \& CHANG, T.T. Drought resistance in cereals Rice: a case estudy. In: MUSSEL,H. \& STAPLES, R.C., eds. Stress Physiology in Crop Plants. New York: Willey Interscience, 1979. p.373-405. 
O'TOOLE, J.C. \& CRUZ, R.T. Response of leaf water potential, stomatal resistance, and leaf rolling to water stress. Plant Physiology, v.65, p.428-32. 1980.

O'TOOLE, J.C. \& GARRITY, D.P. Upland rice soil-plant-water relatioships. In: UPLAND RICE WORKSHOP, Ivory Coast, 1982. Upland rice research. Philippines: IRRI, 1984. p. 395-411.

O'TOOLE, J.C. \& MOYA, T.B. Genotypic variation in maintenance of leaf water potential in rice. Crop Science, v.18, p.873-6. Set/out. 1978.

O'TOOLE, J.C. \& MOYA, T.B. Water deficits and yield in upland rice. Field Crops Research, v.4, p.247-59. 1981.

O'TOOLE, J.C. \& NAMUCO, O.S. Role of panicle exsertion in water stress induced sterility. Crop science, v.23, n.6, p.1093-7, Nov/Dec. 1983.

O'TOOLE, J.C.; CRUZ, R.T. \& SINGH, T.N. Leaf rolling and transpiration. Plant Science Letters, v.16, p.111-14. 1979.

PARICHA, P.C. \& SAHOO, P. Studies on the physiological vaiability in some mutant cultures of rice to resist drought. Oryza, v.12, n.2, p.73-81. 1975.

PASSIOURA, J.B. Effect of root geometry on the yield of wheat growing on stored water. Australian Journal Agriculture Research, v.23, p.745-52. 1972. 
PASSIOURA, J.B. The role of root system characteristics in the drought resistance of crop plants. In: International Rice Research Institute. Drought resistance in crop: with enphasis on rice. Philippines: IRRI, 1982. p.7182 .

PINHEIRO, B.S. Estudo das relações hídricas durante o processo de emissão de panículas e antese do arroz de sequeiro (Oryza sativa L.). Campinas, 1989. 176p. Tese (Doutorado) - Universidade Estadual de Campinas.

PINHEIRO, B.S; MARTINS. J.F.S. \& ZIMMERMANN, E.J.P. Índice de área foliar e produtividade do arroz de sequeiro. II. Manifestação através dos componentes da produção. Pesquisa Agropecuária Brasileira, v.25, n.6, p.873-9, Jun. 1990.

PINHEIRO, B.S. \& RAISSAC, M. Parâmetros fisiológicos relacionados a resistência à seca em arroz de sequeiro. In: III CONGRESSO DA SOCIEDADE BRASILEIRA DE FISIOLOGIA VEGETAL, Viçosa, 1991. Anais. Viçosa, MG. 1991.

PINHEIRO, B.S. \& RAISSAC, M; CARMO, M.P. \& EERREIRA Jr, E. Atributos de resistência à seca da variedade de arroz Rio Paranaíba e seus progenitores de origem africana e nacional. In: REUNIÃO NACIONAL DE PESQUISA DE ARROZ, 5 , Goiania, 1994. Trabalhos Apresentados. Goiânia: CNPAE/EMBRAPA, 1994. P.44.

PINHETRO, B.S.; STEINMETZ, S.; STONE, L.E. \& GUIMARÃES, E.P. Tipo de planta, regime hídrico e produtividade do arroz de sequeiro. Pesquisa Agropecuária Brasileira, v.20, n.1, p.87-94, Jan. 1985. 
QUARRIE, S.A. Cereal yields and drought resistance. Nature, v.285, p.612-3, Jan. 1980.

RENARD, C. \& ALLURI, $K$. Leaf water potential, stomatal condutances and leaf caracteristics of variedades of rice in their response to water stress. Acta Ecologica/Ecologia Plantarum, v.2, n.4, p.339-49. 1981.

SANTANA,E.P.; HECKLER, J.C.; SILVA, J.T.A. da et al. Avaliação crítica dos projetos do PNP-Arroz: área de melhoramento genético - Região Centro-Oeste. In: EMBRAPA. A pesquisa do arroz no Brasil nos anos 80: avaliação crítica dos principais resultados. Goiânia: EMBRAPA, 1994. p.309-23. (EMBRAPA/CNPAE. Documentos, 40 ).

SCHOENEWEISS, D.E. Water stress as a predisposing factor in plant disease. In: KOZLOWSKI, T.T., ed. Water deficits and plant growth. New York: Academis Press, 1978. n.5: Water and plant disease. cap.2, p.61-100.

SCHOLANDER, P.E.; HAMMEL, H.T.; BRADSTREET, E.D.\& HEMNINGSEN, E.A. Sap pressure in vascular plants. Science, v.148. p.339-46. 1965.

SEGUY, L. \& BOUZINAC, S. Gestão dos solos e das culturas nas fronteiras agrícolas dos cerrados úmidos do Centro Oeste. I. Destaques 1992 e síntese atualizada 1986/1992. Convênio RPA/CIRAD-CA. Lucas do Rio verde-MT. Relatório. 1992. $117 \mathrm{p}$. 
SINGH, B.N. \& MACKILL, D.J. Genetics of leaf rolling under drought stress. In: INTERNATIONAL RICE GENETICS SYMPOSIUM, Philippines, 1990. Rice Genetics II. Philippines: IRRI, 1991. p.159-66.

STEINMETZ, S.; REYNIERS, E.N. \& EOREST, E. Caracterização do regime pluviométrico e do balanço hídrico do arroz de sequeiro em distintas regióes produtoras do Brasil: sintese e interpretação dos resultados. Goiânia, EMBRAPA-CNPAF, $\quad$.1, 66p. 1988.

STEPONKUS, P.L.; CUTLER, J.M. \& O'TOOLE, J.C. Adaptation to water stress in rice. In: TURNER, N.C. \& KRAMER, P.J., ed. Adaptation of plants to water and high temperature stress. New York: John Willey, 1980. p.401-18.

SWINDALE, L.D. \& BIDINGER, F.R. Introduction: The human consequences of drought and crop research priorities for their alleviation. In: PALEG, L.G. \& ASPINALI, D. The physiology and biochemistry of drought resistance in plants. Australia: Academic Press, 1981. cap.1. p.2-13

TAYLOR, H.M. Modifying root systems of cotton and soybean to increase water absorption. In: TURNER, N.C. \& KRAMER, P.J., ed. Adaptation of plants to water and high temperature stress. New York: John Willey, 1980. cp.6, p. $75-84$.

TOWNLEY-SMITH, T.E. \& HURD, E.A. Testing and selecting for drougt resistance in wheat. In: MUSSEL, H. \& STAPLES, R.C. Stress physiology in crop plants. New York: John Willey, 1979. p.447-63. 
TURNER, N.C. Adaptation to water deficits: a changing perspective. Australian Journal Plant Physiology, v.13, P. 175-90. 1986 .

TURNER, N.C. \& JONES, M.M. Turgor maintenance by osmotic ajustment, A review and evaluation. In: TURNER, N.C. \& KRAMER, P.J., ed. Adaptation of plants to water and high temperature stress. New York: John Willey, 1980. p.87103.

TURNER, N.C. Drought resistance and adaptation to water deficits in crop plants. In: MUSSEL,H. \& STAPLES, R.C., ed. Stress physiology in crop plants. New York: Willey Interscience, 1979. p.343-372.

TURNER, N.C.; O'TOOLE, J.C.; CRUZ, R.T.; NAMUCO, O.S. \& AHMAD, $S$. Responses of seven rice variedades to water deficits. I. Stress development, canopy temperature, leaf rolling and growth. Field Crops Research, v.13, p.25771. 1986a.

VIEIRA, A.R.R.; STEINMETZ, S. \& BRUNINI, O. Resposta de duas variedadees de arroz à níveis de água no solo. Pesquisa Agropecuária Brasileira, v.26, n.7, p.927-34, Jul. 1991.

YOSHIDA, S. Factors that limit the growth and yield of upland rice. In: IRRI, ed. Major research in upland rice. Philippines: IRRI, 1975. cap.2, p.46-71. 
YOSHIDA, S. \& HASEGAWA, S. The rice root system: its development and function. In: International Rice Research Institute. Drought resistance in crop: with enphasis on rice. Philippines: IRRI, 1982. p.97-114. 


\section{APÊNDICE}

Tabela 09. Relação dos genótipos utilizados nos experimentos

\begin{tabular}{|c|c|c|}
\hline Grupo & Cultivar & Genealogia \\
\hline 1 & CNA 7438 & CICA8/Bico Torto//60 dias \\
\hline 1 & CNA 7307 & Rustic/Tapuripa \\
\hline 1 & CNA 7474 & Tox 939-107-2-101-1B/Col 1*M 312A//Tox 1177-32 \\
\hline 1 & CNA 7479 & IRAT 194-1-2-1B/Col 1*M 312A//Tox 1177-32 \\
\hline 1 & CNA 7470 & Tox 1780-2-1-1P-4/Col 1*M 312A//IAC 47 \\
\hline 1 & CNA 7476 & Tox 1010-24-2-1B/Col $1 * \mathrm{M} 312 \mathrm{~A} / /$ Tox $1780-2-1-1 \mathrm{P}$ \\
\hline 1 & CNA 7479 & Tox 1010-45-1/Col 1*M 312A//Tox 1780-2-1-1P-3 \\
\hline 1 & CNA 7463 & Tox $1010-45-1 /$ Col $1 * \mathrm{M} 312 \mathrm{~A} / /$ Tox $1780-2-1-1 \mathrm{P}-3$ \\
\hline 1 & CNA 7445 & IAC 1246/CICA 8//Rexoro \\
\hline 1 & CNA 7465 & Khaolo*IR8/Col 1*M 312A/RHS 107-2-1-2TB-1JM \\
\hline 1 & CNA 7472 & Tox 1010-24-2-1-1B/Col 1*M312A//Tox 1780-2-1-1P \\
\hline 1 & CNA 6655 & IAC 46/Tox 502-46-ML-83-B \\
\hline 1 & CNA 6481 & CICA8/IAC 165//Agulha Anão \\
\hline 1 & CNA 7444 & Amarelão/IAC 165//Agulha Anão \\
\hline 1 & CNA 7464 & Tox 1010-45-1/Colombia 1/Tox 1718-2-1-1-P-4 \\
\hline 1 & CNA 7468 & Tox1010-24-2-1-1B/Coll*M312A//Tox718-AL-20-1CM-1JM \\
\hline 1 & CNA 7517 & IAC1246/CICA 8/Rexoro \\
\hline 1 & CNA 7286 & CNA 551-1-1B-30/Br Irga 410 \\
\hline 2 & Puteca & Coleta GO \\
\hline 2 & Japonês Claro & Coleta RS \\
\hline 2 & 4 meses branco & Coleta MG \\
\hline 2 & Campininha & Coleta SP \\
\hline 2 & Anão do fim & Coleta CE \\
\hline 2 & Bico ganga branco & Coleta GO \\
\hline 2 & Taguari & Coleta GO \\
\hline 2 & Ferrujão & Coleta MT \\
\hline 2 & Guaíra & Coleta GO \\
\hline 2 & Jaguari CE & Coleta CE \\
\hline 2 & Cutião branco & Coleta PI \\
\hline 2 & Carioquinha vermelho & Coleta GO \\
\hline 2 & Cutião vermelho & Coleta MA \\
\hline 2 & Beira campo & Coleta MG \\
\hline 2 & Arroz de revenda & Coleta MA \\
\hline 2 & Paulistinha & Coleta ES \\
\hline 2 & Casado & Coleta CE \\
\hline 2 & 3 Nenem & Coleta CE \\
\hline 3 & IRAT 13 & Mutante de 63-83 \\
\hline 3 & IRAT 134 & IRAT 13//LUN CHENG1/63-104 \\
\hline 3 & IRAT 101 & Mutante de 63-83 \\
\hline 3 & IRAT $2(63-83)$ & Cruzamento Natural de 506A \\
\hline 3 & IREM 41-1-3 & \\
\hline 3 & IREM 9-3-3 & \\
\hline
\end{tabular}


(continuação Tabela 09.)

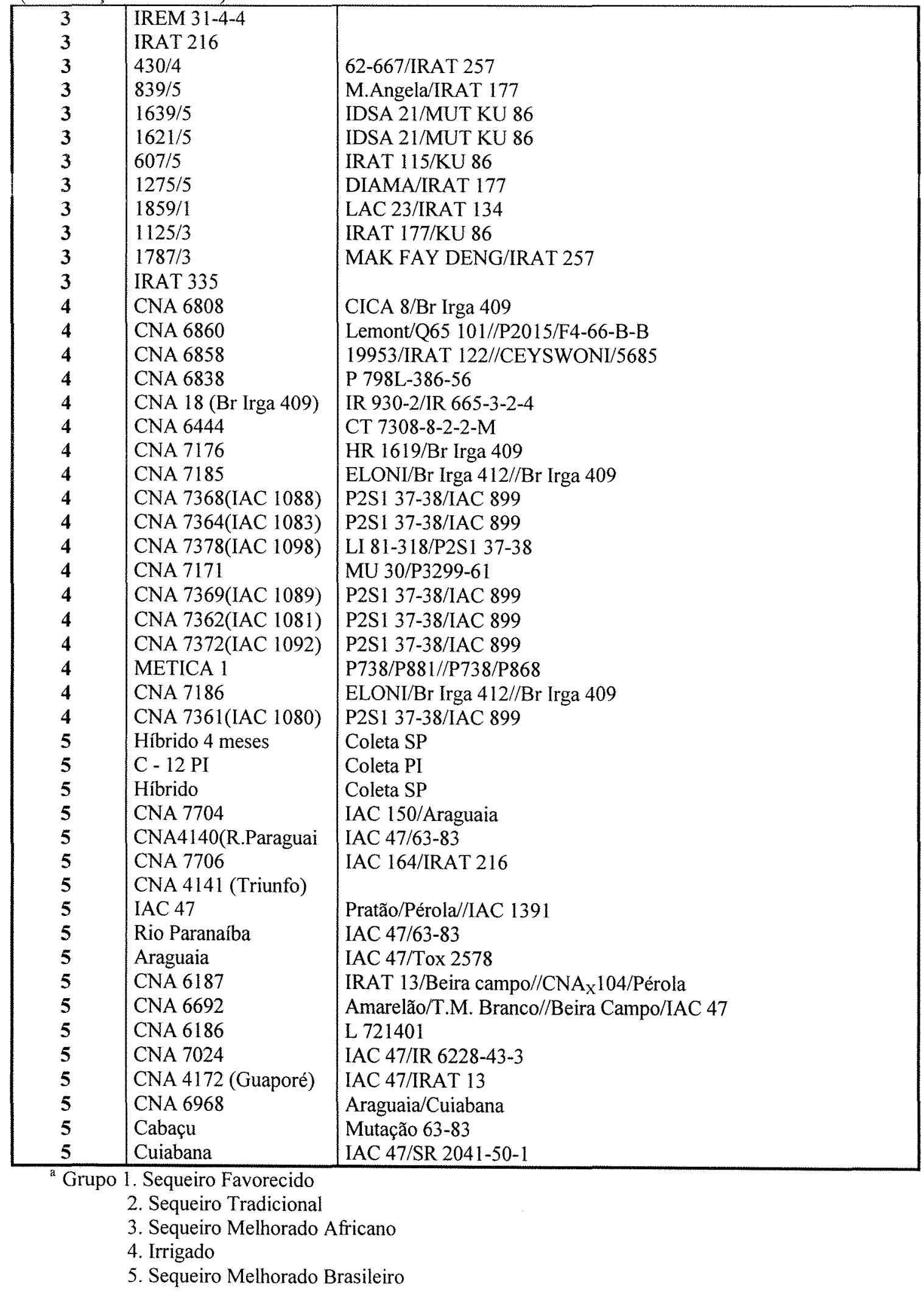

